\title{
José Joaquín de Mora, una biografía intelectual. Los años ilustrados
}

Rafael Cerpa Estremadoyro

Universidad Nacional Autónoma de México

\section{RESUMEN}

El principal objetivo de nuestro trabajo es mostrar la influencia de la llustración en la vida y obra de José Joaquín de Mora, mediante un análisis de sus primeros años de formación. Este periodo de la vida de Mora, poco estudiado por sus biógrafos, es fundamental en tanto que su posterior evolución intelectual, su asimilación de otras teorías e ideas, no es otra cosa que las diferentes respuestas que él tiene a las diferentes problemáticas de su época, teniendo siempre como marco conceptual primero su propia mentalidad ilustrada. A diferencia de otras biografías acerca de este autor, la nuestra pretende además ser intelectual, pues analiza la vida del escritor gaditano en márgenes relativamente claros, es decir, dentro de tradiciones, formas de argumentación y usos del lenguaje, que determinan hasta cierto punto las estrategias de escritura en sus obras.

\section{PALABRAS CLAVE}

José Joaquín de Mora, biografía intelectual, Ilustración española, educación, liberalismo.

\section{ABSTRACT}

The main objective of our paper is to show the influence of the Enlightenment in the life and work of José Joaquín de Mora by analyzing his formative years. This period of his life, scarcely studied and largely unknown by his biographers, is essential for his later intellectual development. His assimilation of other theories and ideas is nothing but the different responses he provides to the various problems of his time always according to the conceptual framework of his own Enlightenment mentality. Unlike 
other biographies about this author, ours also aims to be intellectual, for we examine the life of the writer of Cadiz in relatively clear margins, that is, within traditions, forms of argument and uses of language, which determined to some extent the writing strategies in his works.

\section{KEYWORDS}

José Joaquín de Mora, intellectual biography, Spanish Enlightenment, education, liberalism.

A pesar de la abundante bibliografía que dejó tras de sí Mora al momento de su fallecimiento en 1864, difícilmente podemos encontrar en esta copiosa maraña de textos uno solo que pueda ser considerado por sí mismo como una obra maestra. No sin razón su colega en tantas aventuras periodísticas, Alcalá Galiano', se preguntaba acerca de las razones por las que el gaditano no había alcanzado el reconocimiento de sus contemporáneos: «D. José Joaquín de Mora es uno de los vivos y hábiles autores de la España moderna, y a pesar de eso no ha producido aún ninguna obra importante ni correcta; de donde nace que sea de poca estimación entre sus compatriotas. No solo eso, a pesar de lo mucho que ha leído, es considerado generalmente como un hombre de ciencia algo trivial ${ }^{2}$. Esto no se debía, como recalca ese mismo autor, a la falta de talento de Mora. En realidad, él podía pasar con facilidad por ser uno de los escritores más capaces de toda su generación.

¿Por qué deberíamos entonces continuar estudiando la vida y las obras de este hombre de ciencia algo trivial? En realidad, si bien Mora no produjo obra alguna que pueda ser considerada legítimamente como un clásico de la lengua castellana, al momento de estudiar todos los pormenores de su biografía se puede percibir que fue la propia vida de este autor la que se erige como su verdadera obra maestra, una existencia que se prolongó

\footnotetext{
1 Antonio Alcalá Galiano y Fernández de Villavicencio (Cádiz, 1789-Madrid, 1865). Político y escritor español. Doceañista en su juventud, junto con José Joaquín de Mora en la década de 1810 se opuso a la introducción del Romanticismo reaccionario germánico por Juan Nicolás Böhl de Faber en Cádiz, pero después de su emigración londinense (a partir de 1823) tomó partido por la nueva estética. Véase su «Prólogo» a El moro expósito, de su amigo Ángel de Saavedra, Duque de Rivas, que puede ser considerado el manifiesto del Romanticismo español. Gran orador, defendió el liberalismo exaltado durante el Trienio Liberal, pero luego se pasó a la Masonería y al partido moderado.

2 Antonio Alcalá Galiano, Historia de la literatura española del siglo XIX. La Historia de Alcalá Galiano apareció por primera vez en la revista londinense The Athenaeum (abril-junio, 1834), es decir, 30 años antes del fallecimiento de nuestro autor. El título original de este trabajo era Literature of the Nineteenth Century: Spain. Existen varias traducciones de él. Nosotros hemos utilizado la versión de Antonio Zinny, en Efemeridografía argirometropolitana hasta la caída del gobierno de Rosas (Zinny 1869: 49). También la traducción y edición de Vicente Llorens con el nombre Literatura española del siglo XIX (1969).
} 
durante casi siete décadas y que cristalizó en sí todos los avatares ideológicos e intelectuales de la época. Mora no se conformó con ser periodista o literato de cierta valía; también lo vemos ejerciendo en ramas tan diversas como la educación, la economía, la filosofía, el derecho, la diplomacia o la traducción. Esta heterogeneidad de roles iba a la par con una constante evolución intelectual. Ilustrado y neoclasicista en su juventud, pasará a ser durante la etapa media de su vida romántico y liberal, para terminar en posiciones cercanas al conservadurismo al final de sus días.

No está de más decir que muchas vidas, célebres o anónimas, pueden ser consideradas como obras de arte, aunque podría ser materia de discusión qué es lo que hace que la vida de alguien se convierta en una. Claro está, no es necesario realizar acciones exaltantes o fuera de lo común para alcanzar esto ${ }^{3}$. En parte para mostrar cuán exacta es esta apreciación en el caso del publicista gaditano, en el presente trabajo nos proponemos estudiar su vida, privilegiando las primeras etapas que atraviesa su formación académica, fundamentales para entender las posiciones literarias, filosóficas e ideológicas que asumió durante el periodo que estuvo en América. A diferencia de otras biografías acerca de este autor ${ }^{4}$, la nuestra pretende además ser intelectual.

Aunque para establecer una biografía intelectual de un determinado personaje es hasta cierto punto relevante el análisis de sus escritos, de sus teorías y sus ideas, se debe considerar también cómo él descubre esas teorías e ideas, y cómo se desarrolla su evolución intelectual. A pesar de esto, actualmente se tiende a valorar más la biografía intelectual en tanto que puede proporcionar a aquel que la práctica un medio adecuado para anclar las ideas de un autor en los diferentes contextos en los que se producen estas ${ }^{5}$. Así, esta forma de biografía obliga al que se adentra a ella a tomar en cuenta la tensión existente entre un autor determinado y su contexto intelectual, político y social. Esta tensión, lejos de ser anodina, expresa bastante bien el hecho de que se puede percibir a un determinado personaje tanto como receptor del medio en el cual se desenvuelve, pero también como agente que sobrepasa los límites que impone su

3 Por lo general, se atribuye al pensador francés Michel Foucault la idea de la vida en tanto que obra de arte, aunque esta concepción sea deudora del esteticismo decimonónico asociado a la filosofía de Nietzsche. Para el filósofo alemán, la autocreación era una cuestión de abrazar la multiplicidad de todos los yo posibles (Nietzsche 1996: 218). En el caso de Foucault, el punto de partida es la idea de que el yo no nos es dado. Siendo esto así, se puede extraer la siguiente consecuencia práctica: somos nosotros mismos los que construimos nuestro yo como obra de arte (entrevista a Foucault publicada en la revista Vanity Fair de 1983).

4 Las dos más notables son sin duda la de Amunátegui (1888) y la de Monguió (1967).

5 Dubnov 2012: 11. 
contexto, al punto que pretenda modificarlo y moldearlo ${ }^{6}$. Tratando de sintetizar ambas posiciones, dos son las estrategias de interpretación que nosotros empleamos en la presente biografía. En primer lugar, la vida de Mora se desarrolla dentro de márgenes relativamente claros, es decir, dentro de tradiciones, formas de argumentación y usos del lenguaje, que determinan hasta cierto punto las estrategias de escritura en sus obras. Por otro lado, para nosotros los textos de Mora deben ser considerados en tanto réplicas que da este autor a los problemas literarios, filosóficos e ideológicos, a los que debe hacer frente a lo largo de su vida. De este modo, la evolución intelectual del escritor gaditano, su propia asimilación de teorías e ideas, no es otra cosa que las diferentes respuestas que tiene este a las problemáticas de su época. A esto nos debe conducir primordialmente el análisis de sus obras. No obstante, los ideales de la llustración, que adquirió durante sus primeros años de formación, tendrán un papel decisivo al momento de decidir cómo se plantean estas réplicas o qué otras teorías está dispuesto a asimilar.

Se puede distinguir con claridad cuatro periodos distintos en la vida del escritor gaditano7 ${ }^{7}$ Durante sus primeros años en España (1783-1823), Mora recibió una formación inicial que sin dificultad puede ser localizada dentro del catolicismo ilustrado y del neoclasicismo, lo que se reflejaba también en las posiciones literarias y filosóficas que tuvo en ese tiempo. Un segundo periodo lo constituye el tiempo intenso de su exilio en Londres (1823-1827), en el cual reforzó su tendencia liberal en política a causa del contacto que tuvo con el sistema político inglés, al punto que se vuelve un defensor de la forma representativa de gobierno. En sus intereses literarios se produjo igualmente un cambio notable, pues del rígido clasicismo de inspiración francesa adoptó posiciones que pueden considerarse próximas al romanticismo, como resultado de su estudio de los escritores ingleses (por influencia de José María Blanco White). El tercerperiodo lo representa la fructífera labor que realizó en América (1827-1842). Se inicia con su traslado a Argentina en 1827 por invitación del presidente Rivadavia. Durante los primeros cuatro años en Argentina y Chile (18271831), su actividad literaria declinó significativamente debido en parte a su intensa participación en la vida política y educativa de estos países. Posteriormente, en el Perú y Bolivia tuvo más tiempo para la escritura. De

6 Ibíd. Se puede entender mejor los textos, por modestos que estos sean, si los consideramos como productos de la actividad intelectual de un autor, pues la forma privilegiada como él responde a las ideas y las apreciaciones de otros autores es exclusivamente a través de sus escritos.

7 Trease 1953: i-iii. Si bien hemos seguido la periodización presente en el excelente trabajo doctoral de este estudioso norteamericano, le hemos realizado importantes modificaciones. 
su última etapa en América data una colección de poemas en 1836, que el autor volverá a publicar en España con importantes modificaciones, y sobre todo su obra más conocida, Leyendas españolas (1840). Después de permanecer un tiempo como representante de Santa Cruz en Londres, regresa a España en 1842. El último periodo de su vida (1842-1864) puede ser caracterizado como de moderación de sus puntos de vista políticos y literarios. A lo largo de 1850, el escritor fue nombrado varias veces cónsul de España en Londres. En esta postrera etapa de su vida, el literato colaborará en La América, Crónica Hispano-Americana, donde publicará tanto reseñas bibliográficas como artículos literarios, filosóficos y de divulgación científica.

De estos cuatro periodos, nos interesa sobre todo el primero, el de su formación inicial. Nuestro trabajo se propone de este modo mostrar la impronta de la llustración en la obra de José Joaquín de Mora, a través del estudio de sus primeros años de formación intelectual. Esta etapa debe ser considerada como fundamental para comprender la posterior evolución intelectual del escritor gaditano. Su asimilación de teorías e ideas no es otra cosa que las diferentes respuestas que tiene a las problemáticas de su época, y tiene como telón de fondo sus convicciones de hombre ilustrado.

A pesar de que algunos intérpretes han dado algunas luces acerca de esta influencia, siendo el principal de ellos Monguió, no se la ha destacado desde nuestro punto de vista lo suficiente. En realidad, si se puede señalar una constante en el pensamiento y en la obra de este autor inconstante, esta es precisamente el mantenimiento de los ideales ilustrados a lo largo de su vida. Esto decidirá también la manera en que asimila algunas de las corrientes intelectuales que influirán en él, que van desde el Romanticismo, la filosofía escocesa o el liberalismo. El estudio de su formación inicial nos permite también comprender con más profundidad otros aspectos esenciales de la vida posterior del escritor gaditano, como es la fructífera labor que realiza en Hispanoamérica. Por último, nuestro trabajo pretende contribuir al conocimiento de la pervivencia de la llustración en el siglo XIX tanto en España cuanto —en menor medida - en los países de la América hispana.

\section{Un siglo de Ilustración y de progreso moral}

En muchos de sus escritos, Mora se sitúa a sí mismo como heredero de la filosofía de las luces y del progreso moral en la historia. Al igual que la mayor parte de los ilustrados, el escritor gaditano consideraba que el progreso en conocimientos científicos y técnicos conllevaba siempre a un progreso de orden moral. Muchas de las posiciones que adoptó a lo 
largo de su vida se pueden entender a partir de este principio básico de la llustración. Así, no debe sorprender su optimismo por las virtudes de la educación, pues al propagar los frutos de la nueva ciencia conducía con igual fuerza al perfeccionamiento del género humano. Esta convicción la mantendrá incluso en la última etapa de su vida. De este modo, en el discurso inaugural del curso de filosofía de la historia que enseñó en el Ateneo científico y literario de Madrid el año 1851 dirá: «Pero os he dicho que la ciencia, además de ocuparse de las necesidades positivas de la vida, influye en los progresos intelectuales de la humanidad ${ }^{8}$. Si el progreso en el conocimiento y la cultura implica un progreso moral, se puede afirmar con validez su contrapuesta; a saber, que el declive moral de una nación es consecuencia por lo general de un declive al nivel de los conocimientos científicos y técnicos. Algunos ilustrados irán más allá y considerarán que la condición esencial para la existencia misma de la llustración es la liberación del despotismo. Así, Holbach dirá en un texto que será traducido por Mora: «Los hombres no serán nunca virtuosos sino es cuando conozcan que es útil el serlo: conocerán este interés cuando tengan luces, y las tendrán cuando dejen de ser esclavos del despotismo y de la superstición»?.

En un pasaje de una carta de 1761, Denis Diderot resume bastante bien el postulado básico de este movimiento intelectual: «La llustración es un bien del cual se puede abusar, sin duda; la ignorancia y la estupidez, compañeras de la injusticia, del error y de la superstición, siempre son males» ${ }^{10}$. La llustración es un bien que es descrito implícitamente aquí como la adquisición de conocimientos y el cultivo de la inteligencia, que están acompañados siempre de la justicia, la certeza y las creencias fundamentadas en bases científicas. Más que poseer un significado puramente descriptivo, el término bien empleado por Diderot tiene un sentido prescriptivo, equivalente a una guía de acción ${ }^{11}$, que señala al género humano

8 El Clamor Público, 5 de noviembre de 1851. Sección literaria. En esto coincidía Mora con un ilustre contemporáneo suyo, Gaspar Jovellanos, quien en la primera cuestión de su Memoria sobre educación pública (1802) afirmaba: «Las fuentes de la prosperidad social son muchas; pero todas nacen de un mismo origen, y este origen es la instrucción publica. Ella es la que las descubrió, y a ellas están subordinadas» (Jovellanos 1802: 68).

9 Holbach y Mora 1823: 253. En el original francés: «Les hommes ne seront vertueux que lorsquils trouveront qu'il est utile de l'être; ils ne sentiront cet intérêt que lorsqu'ils auront des lumières; ils ne seront éclairés que lorsqu'ils cesseront d'être esclaves du despotisme et de la superstition» (1793: 152). El razonamiento puede ser formalizado de la siguiente forma:

Si los hombres cesan de ser esclavos del despotismo, entonces adquirirán luces.

Si los hombres adquieren luces, entonces conocerán ese interés [ser virtuoso es útil].

Si los hombres conocen que ser virtuoso es útil, entonces serán virtuosos, cita].

:. Si los hombres cesan de ser esclavos del despotismo, serán virtuosos [conclusión implí-

10 Carta a la Mademoisselle Volland, 22 de setiembre de 1761, XIX, 51-2.

11 Acerca del uso prescriptivo de bien como guía de acción, véase Hare 1952. 
sumido en la ignorancia, el error y la superstición, lo que debe hacer para salir de ese estado.

Además, los pensadores de las luces percibían la propia historia humana como un progreso constante hacia una condición cada vez mejor en términos de libertad, justicia, paz, y bienestar ${ }^{12}$. Ante la pregunta sobre si la especie humana está en continuo progreso hacia lo mejor ${ }^{13}$, el más célebre pensador de esta corriente, Immanuel Kant, dará una respuesta afirmativa, sin ambigüedad alguna, señalando que solo con la llustración comenzó la época en la que la humanidad podía salir de su minoría de edad y moverse triunfalmente hacia su emancipación debido a las solas fuerzas de la razón. Frente a aquellos que no compartían tal optimismo, exaltado, Denis Diderot exclamará en una carta dirigida a la emperatriz Catalina II: «iMaldito sea el impertinente que no puede percibir que nunca antes la llustración fueron tan populares, y que esta popularidad nos puede conducir a algo útil!» ${ }^{14}$.

El optimismo ilustrado respecto a las virtudes que acarreaban los progresos en ciencia y en educación se manifiesta con claridad en los dos grandes proyectos que salieron a la luz en el siglo XVIII: la Enciclopedia y los museos. Mientras que en el primer caso se trataba claramente de una empresa casi individual, el segundo sobre todo presentaba un carácter institucional. Con las primeras enciclopedias en el siglo XVIII se hará tangible el deseo ilustrado de transmisión de los progresos científicos y artísticos. En primer lugar, tenemos la Cyclopaedia, o Diccionario universal de artes y ciencias, de Ephraim Chambers, publicado en Londres, en 1728, que sirvió de inspiración para la monumental Enciclopedia o Diccionario de las ciencias, las artes y los oficios, 1751-1772, de Denis Diderot y Jean d'Alembert. En ambos casos, se pretendía organizar de forma racional los conocimientos disponibles en la época, sean estos científicos, técnicos, artísticos y filosóficos, para difundirlos después en el mayor número de personas. Posteriormente, con el afianzamiento de la opinión pública, serán las publicaciones periódicas como los diarios y las revistas las que plasmarán el antiguo proyecto ilustrado. La Crónica Científica y Literaria, periódico madrileño de divulgación científica editado por Mora entre 1817 y 1820 , que se proponía como se señalaba en su prospecto

\footnotetext{
12 Bobbio 2001: 119-136. Lessing llegará a decir, lleno de esperanza, en su célebre escrito Educación del género humano (1780): «[...] vendrá, seguramente tendrá lugar esta era de perfección del hombre [...]».

13 Kant 2003: «¿La especie humana está en constante progreso hacia lo mejor?».

14 Diderot y Catalina II, ibíd.: 296. Sin embargo, en el siglo XX, debido a las dos guerras mundiales y la masacre sin precedentes que produjeron, la idea misma de progreso fue puesta en cuestión por los intelectuales europeos.
} 
favorecer «á la ilustración científica y literaria, fuente de la verdadera cultura, y apoyo firme de la sana moral», puede ser un correlato, aunque a un nivel mucho más modesto, de las Enciclopedias inglesas y francesas, publicadas décadas antes ${ }^{15}$.

Otro tanto sucedía con otra gran creación ilustrada: los museos. Si la nobleza europea con los gabinetes de curiosidades había participado ya en la conservación de las obras de arte, fue solamente con la Revolución francesa que se crearon los primeros museos en el sentido moderno de este término y se descubrió el concepto de patrimonio. Según esta perspectiva, el museo, además de constituir al igual que la Enciclopedia una forma organizada de la experiencia, era un medio de enseñanza y educación, de difusión del conocimiento, que no solo involucraba el arte, sino también la ciencia, la tecnología y la historia ${ }^{16}$. Con su instauración, se trataba asimismo de proteger las obras de arte contra el vandalismo revolucionario. Además, proporcionaban al gran público el patrimonio cultural de una nación que hasta épocas recientes estaba reservado a la esfera privada. El conocimiento pasaba de este modo de la esfera privada a la esfera pública. No es casual que Mora publicase en Londres una revista con el título Museo Universal de Ciencias y Artes $^{17}$, con la que pretendía poner al alcance del mayor número de personas el acervo literario, científico y técnico existente en la época.

Aunque sea desde todo punto de vista imposible proporcionar una definición completa de lo que es la llustración, se puede, no obstante, señalar algunas constantes, que encontramos con cierta facilidad en las obras de los pensadores inscritos en esta corriente. Como veremos, no es difícil identificar explícita o implícitamente, estas cuatro características en los propios escritos de Mora, lo que haría de él en cierta forma un heredero de esta corriente de pensamiento.

Primer rasgo de los ilustrados lo constituye el espíritu crítico, omnipresente prácticamente en todos los ilustrados, entendido como la capacidad de desprenderse de todos los mandatos, comenzando por los de la

\footnotetext{
15 En realidad, por el costo exorbitante que representaba el conjunto de 30 volúmenes de la Enciclopedia solo tuvieron acceso a ella los miembros de las clases acomodadas, como la burguesía, el clero o la administración real. Por ese motivo, los periódicos fueron el medio propicio para cumplir el fin de propagación de las luces, tal como lo hacen ver los redactores del Mercurio Peruano: «El espíritu del siglo es propenso a la ilustración, la humanidad y la filosofía. La América, que desde muchos tiempos se hallaba poseída de estas mismas ideas, se ha unido insensiblemente en adoptar un medio muy oportuno para transmitirlas: este es el de los periódicos» (28-4-1791: 308).

16 Schaer: 2007.

17 Museo Universal de Ciencias y Artes, Londres. Lo publica R. Ackermann, en su Repositorio de Artes, 101 Strand, trimestral, julio de 1821 a octubre de 1826, 2 tomos, I (1824-1825), 384 pp. y II (1826), 260 pp. El director y redactor de esta publicación fue Mora.
} 
naturaleza para elevarse hasta los propios de la sociedad, a fin de someterlos al tribunal de la propia razón. El hombre es libre, en el sentido de que no es esclavo de su condición física o de su propia historia. En la base de este culto del espíritu crítico, se encuentra el método cartesiano, que preconizaba no considerar como verdadero algo que no lo conociese evidentemente como tal. De allí se expande con la llustración a dominios tan diversos como la política, la moral, y la religión. La duda sistemática se instala de este modo en el discurso, poniendo en cuestión conceptos como tradición o autoridad. Se rechaza con ello los argumentos basados únicamente en la autoridad, sea esta política, filosófica o eclesiástica ${ }^{18}$.

La segunda característica del movimiento ilustrado es la concepción racional de la ciencia fundada en el principio de razón suficiente ${ }^{19}$ y en los métodos de observación y de experimentación. En el primer caso se parte del principio general que debemos proporcionar siempre razones suficientes de la verdad (o de alta probabilidad) de nuestras opiniones. De acuerdo con una opinión corriente en el siglo XVIII, este es el fundamento del cual dependen todas las verdades contingentes ${ }^{20}$. Este principio, que se puede encontrar esbozado en algunos textos de la Antigüedad y del Medioevo, se formula de manera definitiva en la época moderna, pasando a ser una pieza maestra en la fundamentación científica. En su primera obra publicada, la Exposición geométrica de principios de la filosofía de Descartes (1663), Spinoza establece en el undécimo axioma que: «No existe nada, de lo que no se pueda pedir cuál es la causa (o razón), de por qué existe» ${ }^{21}$, que puede ser considerado como una de las versiones modernas que adquiere el principio de razón suficiente ${ }^{22}$. El ejemplo característico de su aplicación lo constituye el célebre principio de inercia: un cuerpo no cambia ni de velocidad ni de dirección en tanto que otro cuerpo no modifique su velocidad y dirección. El conjunto de la prueba reposa en la utilización del principio de razón suficiente, es decir que no puede haber efecto sin causa, o que las mismas causas producen los mismos efectos ${ }^{23}$. Si el

\footnotetext{
18 En filosofía, la autoridad principal la constituía sin sorpresa Aristóteles. Feijoo llegó a escribir estas palabras acerca de la percepción que se tenía entonces de su influjo: «Es imponderable el daño que padeció la filosofía por estar tantos siglos oprimida debajo del yugo de la Autoridad» (Teatro crítico, VIII, IV, 10).

19 Llamado también principio de causalidad.

20 Enciclopedia, vol. 31, p. 970 . En otros términos, es el principio de todas los juicios sintéticos a priori. En la actualidad se considera que todos estos intentos de justificación conducen a un trilema: nos obligan a elegir entre la regresión infinita, círculo lógico, o el dogmatismo. 21 «Nulla res existit, de qua non possit quaeri, quaenam sit causa (sive ratio), cur existat» (Principia Philosophiae Cartesianae, p. 124). (Spinoza, Vloten y Land 1914: 124). Este axioma se encuentra en la primera parte de este libro.

22 En general, el principio de razón suficiente puede ser representado de la siguiente forma: (PRS)=Para cada hecho F debe existir una explicación de por qué F existe. Melamed y Lin: 2013. 23 Es objeto de discusión si este principio es puramente apriorístico o está determinado
} 
principio de razón suficiente estipula que debemos dar razones de la verdad de nuestras opiniones, la forma usual de justificar o proporcionar la verdad de una proposición era mediante en los métodos de observación y de experimentación. En Europa, Bacon será considerado como el fundador de la nueva ciencia moderna. En el caso de España, debido a Benito Jerónimo Feijoo, quien luchó implacablemente por divulgar estos métodos a través de todo el país, hacia 1725 comenzó a instaurarse una actitud completamente nueva en el campo de las ciencias ${ }^{24}$. "Hay que preferir siempre la experiencia, dirá este autor en su Teatro crítico, a todo raciocinio ${ }^{25}$. La consecuencia más importante de este proceso de racionalización del entendimiento es lo que Max Weber llama el desencantamiento del mundo, el declive de las creencias religiosas o mágicas como medio para explicar los fenómenos, que se acompaña de una pérdida de sentido en el mundo, en tanto que este puede ser explicado científicamente ${ }^{26}$. De hecho, a partir de que todo es explicable, no se busca más el significado oculto de las $\operatorname{cosas}^{27}$. La naturaleza no presenta más misterios. En términos prácticos, esto se expresa en una lucha contra la superstición y el animismo, por lo cual se produce una desacralización de la naturaleza, en tanto que se la concebía anteriormente como atravesada por fuerzas ocultas.

Una tercera característica en el pensamiento ilustrado es la crítica de la positividad de la ley, que se expresa en la oposición que estos autores establecían entre derecho positivo y derecho natural. De la misma manera, se puede hablar de religión positiva por oposición a la religión natural. Si por ley positiva se entiende la que está vigente, la que es establecida por una determinada comunidad, se puede constatar con facilidad que muchas veces el derecho positivo es injusto, y autorizó según los ejemplos que se proporcionaban en aquel entonces la esclavitud o la tortura. Se trataba entonces de criticar el derecho positivo, cuando se juzgaba esto necesario, a partir de un derecho racional, que sea al mismo tiempo justo e igualitario. Esta crítica era posible debido a que el ser humano poseía algún

empíricamente. Según Poincaré, las demostraciones de la ley de inercia basadas en este principio, presuponen siempre que se ha determinado empíricamente la naturaleza de aquello que se debe conservar. De esta forma, es necesario que la experiencia intervenga para proporcionar a este principio un contenido determinado (La ciencia y la hipótesis, citada por Firode). Posee una dimensión a priori en la medida en que expresa de manera efectiva el principio de causalidad, pero racional en cuanto a su forma y empírica en su contenido. D’Alembert y Firode 2001: 89.

24 Sarrailh 1979: 414.

25 Teatro crítico, citado por Sarrailh 1979: 414. Como lo señala este hispanista, él fue el primero que afirma que «en la medicina es todo experimental» (ibíd.).

26 Gauchet 1985.

27 lbíd. 
grado de conocimiento, tanto por la razón como por la experiencia, de la ley o derecho natural ${ }^{28}$. Esta crítica se extendía también a las tradiciones, debiéndose conservar solo las mejores entre ellas, pues el criterio para mantenerlas no podía ser la antigüedad, sino su propia naturaleza ${ }^{29}$. Lejos de representar una actitud conservadora, la defensa del derecho natural por parte de los pensadores ilustrados puede entenderse incluso como una posición hipercrítica del estado actual de la sociedad. En el caso del escritor gaditano, el derecho natural quedaba reducido a «una ciencia de observación, como lo es la química, y toda la dificultad consiste en ligar los hechos averiguados de modo que de su universalidad pueda resultar un principio que merezca el nombre de ley ${ }^{30}$. No obstante, lo que se observa no es otra cosa que el orden establecido por Dios. De este modo, la teología natural constituye para él el fundamento último del derecho natural. Siguiendo esta perspectiva, él define la ley natural como «el orden regular y constante de los hechos, por los cuales Dios rige el universo: orden que su sabiduría presenta a los sentidos y a la razón de los hombres para que sirva de regla igual y común a sus acciones y para guiarnos hacia la perfección y la felicidad ${ }^{31}$.

Una cuarta característica es el profundo significado político y de renovación social, que tenía la llustración desde sus inicios, que hace de este movimiento algo más que una simple corriente de pensamiento. Encontramos esta relevancia de lo político en obras como el clásico opúsculo de Immanuel Kant Respuesta a la pregunta: ¿Qué es la ilustración? o en los textos de Rousseau ${ }^{32}$. El tema central del opúsculo kantiano es la salida del hombre de su minoría de edad, un estado artificial producido tanto por la voluntad de poder de los regímenes políticos como por la negligencia y cobardía del propio ser humano. Al contrario, la mayoría de edad es el estado natural del ser humano concebido como libre y autónomo.

Buena parte de estos autores propugnaban, no un cambio total de régimen, sino más bien uno que permita la salida de la minoría de edad de

28 Se puede encontrar esta crítica al derecho positivo ya en la Antigüedad, en autores como Cicerón. En su tratado De legibus, él afirma: «Lo que es más insensato es de pensar que todo lo que está reglamentado por las instituciones o las leyes de los pueblos sea justo. ¡Qué! ¿Incluso las leyes de los tiranos?»(De Leg., I, XV, 42).

29 De Leg., II, XVI, 40.

30 Curso de Derechos, p. xvii. Curso de Derechos del Liceo de Chile, por don José Joaquín de Mora, director de aquel establecimiento, tomo I, Santiago de Chile, Imprenta Republicana, 1830, 127 pp. [Derechos Natural y de Gentes].

31 Curso de Derechos de Liceo, Primera parte, Lección primera. Los subrayados en negrita son nuestros. Véase también su definición de derecho natural: «Por Derecho Natural entendemos una reunión de facultades que residen en el hombre, y cuya conservación, que está autorizado a defender por la misma naturaleza; es necesaria a su felicidad y a su perfección» (ibíd.).

32 Kant 2004. 
la población. Este régimen para buena parte de ellos era el despotismo ilustrado, que debía consentir la libertad de pensamiento y la autonomía, al mismo tiempo que se constituía como garante del mantenimiento del orden. Si bien se mantenía la monarquía, conservando el rey el derecho a veto, la facultad de legislar pertenecía al pueblo. Así, si bien a la cabeza del Estado seguía estando el rey, en el plano legislativo pasaban a ser repúblicas. El Estado ilustrado se configuraba además como un Estado educador, que pretendía elevar la cultura de la mayoría, al menos en teoría. Esta forma de gobierno aspiraba también a la paz, pues el bienestar del pueblo era sobre todo la desaparición de la guerra ${ }^{33}$. En el caso de España, se vivía algo paradójico. A pesar de que durante los regímenes de Carlos IV y sobre todo Fernando VII la monarquía era de tipo despótica o absolutista, en la práctica los hombres de la minoría ilustrada estaban convencidos de que vivían bajo una monarquía moderada y casi liberal ${ }^{34}$.

\section{Mora, primeros años}

Algunos autores han recalcado la gran escasez de fuentes acerca de la vida del escritor gaditano, principalmente las que se refieren a su primera etapa $^{35}$. Como lo señala el hispanista francés Camille Pitollet, este escritor tan fecundo optó por permanecer, en buen español, en silencio acerca de sus diversas fortunas ${ }^{36}$. Incluso si uno emprende un estudio detallado de sus obras, no encontrará en ellas (a diferencia de los escritos de tantos otros hombres de letras) más que escasas referencias autobiográficas.

Don José Joaquín de Mora nació en Cádiz el 10 de enero del año 1783. De acuerdo con Ferrer del Río en su Noticia necrológica de $1864^{37}$, la familia del escritor gaditano gozaba de una buena posición entonces. Su padre, Juan de Mora, era un reconocido abogado, que se desempeñaba a la sazón como fiscal del tribunal militar de aquel distrito. De su madre tan solo se conoce el nombre, Micaela Sánchez ${ }^{38}$. Signo de su pertenencia a la burguesía gaditana era su domicilio en Chiclana, lugar de residencia

33 Jovellanos dirá en el Informe acerca de la ley agraria (1795): «Para demostrar esta proposición bastaría considerar que la guerra forma el primer objeto de los gastos públicos» (95). 34 Sarrailh 1979: 579.

35 Pitollet 1909: 48. Las principales noticias biográficas que disponemos de esta primera etapa son las siguientes: Ocios (1824), Mellado (1848), Ferrer del Río (1864), Knight (1867) y Revista de España (1886).

36 «Cet écrivain, si fécond, est resté, en bon Espagnol... muet jusqu'au bout sur ses fortunes diverses» (Pitollet 1909: 50). Como se puede comprobar, nosotros no ofrecemos una traducción literal del pasaje indicado de Pitollet.

37 La América. Crónica Hispano-americana, Madrid, 12 de noviembre de 1864, año VIII, número 21.

38 Ferrer del Río 1864. También en Knight 1867: 368 y Pitollet 1909: 51. Los nombres de los padres de Mora los proporciona Pitollet (1909: 51). 
preferido por la mesocracia local ${ }^{39}$. El propio Ferrer del Río describirá el ambiente que se respiraba en ese entonces en Cádiz:

Aún reinaba Carlos III, de feliz memoria, y en prosperidad se veía todo, lo mismo la instrucción pública y la industria que la agricultura y el comercio; emporio del ultramarino era Cádiz siempre, bien que ya estuvieran habilitados otros puertos españoles para el tráfico libre con nuestras colonias. Allí concurrían muchos extranjeros, y sin embargo ni el idioma francés, tan extendido ahora, se cultivaba generalmente (Ferrer del Río 1864).

El hecho de haber nacido en Cádiz, que Ferrer del Río retrata aquí como el «emporio del ultramarino», permitiría entender quizá ese interés por la economía y el libre comercio, que acompañó a lo largo de su vida al escritor. Se puede considerar igualmente que el contacto temprano con el otro, el extranjero, con toda su carga cultural, facilitó no solo el dominio de lenguas que Mora manifestó desde su primera juventud, sino también la relativa facilidad con la que se adaptó en los diferentes países que le tocó vivir y desplegar su actividad.

Era la Cádiz de entonces, además, uno de los epicentros del movimiento liberal en España. Allí encontraron refugio los jóvenes partidarios de esta causa. Cantero García recrea la animación que se vivía entonces en aquella ciudad: «Pese a lo hostil del momento, reina entre ellos la alegría al saberse cercana la gestación de una nueva España. Entre discursos, proyectos políticos, tertulias y contactos amistosos, Martínez de la Rosa entabla contacto, entre otros, con José Joaquín de Mora, Toreno, Alcalá Galiano... $\gg^{40}$. Allí se promulgó también la célebre Constitución liberal en 1812, que tendrá en la Europa continental un prestigio que ninguna otra carta magna igualará ${ }^{41}$. El propio Bentham consideraba la Constitución de Cádiz superior en muchos puntos a la británica: «iPueblo de Europa! Si has dado gracias al Altísimo por haber puesto ante tus ojos el Código Constitucional español, da también gracias por no haber puesto ante ti la visión del código inglés» ${ }^{42}$. Incluso el término liberal aplicado a un partido

39 Pitollet 1909: 51.

40 Cantero García 2004: 6. Este autor se refiere a José María Queipo de Llano (1786-1843), conocido también como Conde de Toreno, político liberal, miembro de las Cortes de Cádiz, que promulgaron la Constitución de 1812.

41 Sobre este punto, ver Llorens 1954: 12. Este autor explica al inicio de su Liberales y románticos las razones por las que se produce con singular fuerza el liberalismo en Cádiz. Al estar situada sobre una pequeña isla, se mantuvo siempre libre. Cuando las tropas napoleónicas ocuparon gran parte del territorio español, esta ciudad fue una de las pocas que se mantuvo ajena al yugo francés. De esta forma, al ordenar Napoleón dictar en Bayona una Constitución política para España, los representantes de los españoles libres pudieron votar otra en Cádiz en 1812 (9).

42 Jeremy Bentham, Rid yourselves of Ultramaria (1820: 193). Esto no impedirá que el utilita- 
político o a individuos, como lo indica Alcalá Galiano en un célebre artículo publicado en La América ${ }^{43}$, empezó a usarse por primera vez en esa ciudad en 1811. Si bien no se puede afirmar que nuestro escritor fue un liberal de primera hora, sus acercamientos inopinados al régimen absolutista de Fernando VII en aquel tiempo impiden afirmar esto ${ }^{44}$; no obstante, su posterior adhesión a este movimiento pareciera haber surgido en medio de este ambiente de gran sobresalto y de agitación política.

De sus primeros estudios, se conoce igualmente muy poco. Mora habría aprendido desde muy joven el latín, idioma que llegó a dominar casi a la perfección, y las lenguas francesa e inglesa ${ }^{45}$, incluso antes de ingresar en el Colegio de San Miguel de Granada. A esto se añadiría una educación inicial, impregnada por lo que algunos llaman el catolicismo ilustrado ${ }^{46}$, caracterizado, entre otras cosas, por el espíritu crítico, el rechazo de las formas de religiosidad popular que se expresaba tanto en la crítica de leyendas y milagros discutibles como en el anhelo de purificar la religión de cualquier superstición, el episcopalismo, el regalismo y galicanismo, la reforma eclesiástica, el rigorismo moral, oposición al escolasticismo, el antijesuitismo y el rechazo del probabilismo, y una cierta actitud comprensiva hacia los protestantes ${ }^{47}$. Según un punto de vista bastante extendido, esta forma de catolicismo tuvo un fuerte vínculo con una corriente teológica que sacudió buena parte de la Europa ilustrada: el jansenismo.

rista inglés presente críticas a esta carta magna.

43 Orígenes del liberalismo español, en La América, 12 de julio de 1864.

44 A pedido de Fernando VII, Mora cumplió una misión diplomática en Italia en 1819. MeIlado proporciona una versión bastante sucinta de este episodio: «Fernando VII, que lo apreciaba mucho, le confió en 1819, una comisión importante á Roma, y de vuelta de ella halló al país regido por el sistema constitucional, y se alistó en las filas liberales» (ibíd.). Es importante decir que entre los que apoyaban la monarquía existía dos grupos: los ilustrados y los absolutistas. Los que se inclinaban al establecimiento de una monarquía ilustrada en España pretendían sentar las bases de un régimen constitucional a la cabeza del cual se encontraba el rey con poderes limitados por el parlamento. El propio reinado de Fernando VII oscilará entre una monarquía de tipo absolutista a una de carácter ilustrado (1820-1823).

45 Revista de España de 1866. Sobre el conocimiento de estas lenguas importantes para su labor de traductor y difusor de obras literarias, históricas y filosóficas, francesas e inglesas, Ferrer del Río dirá: «Lo [el francés] poseyó Mora con perfección desde los primeros años, a la par que aprendía a saborear las bellezas de los clásicos latinos, y notablemente familiarizado estaba con la lengua inglesa, cuando su padre le envió a proseguir los estudios a la Universidad de Granada» (ibíd.).

46 Algunos autores consideran que el catolicismo ilustrado es la prolongación de la reforma tridentina, que enfatizaba la cultura bíblica y la importancia de la catequesis, dando lugar también a la aparición de nuevos temas relacionados con la cultura de los siglos XVII y XVIII. 47 Ver Viaño 2003: 24, etiam Merkle, S., Die Kirchliche Aufklarung im katholischen Deutschland, Berlín, 1910, citado por Morgado García 1991: 105. Estos autores mencionan otras características, como la crítica de los excesos en las formas externa de culto, la defensa de la lectura en lengua vulgar de las Sagradas Escrituras, la crítica de la oratoria barroca, el hincapié en las auténticas fuentes que son la Biblia, la Patrística, los Concilios y las enseñanzas de los papas. 
Si a partir de una lectura atenta de sus escritos uno puede tener pocas dudas acerca de la educación ilustrada que recibió nuestro autor, es el propio Mora el que se encargará de sugerir el componente jansenizante en su formación primera. En una carta dirigida al constructor ferroviario residente en Tacna, José Hegan, a quien había conocido durante el tiempo en que fue cónsul en Inglaterra en la década de 1850, expresa que su educación inicial fue impartida por un santo clérigo jansenista, sin precisar no obstante el nombre ${ }^{48}$. Con esta alusión, nuestro personaje manifestaba su interés por un escrito de otro reputado jansenista, el sacerdote tacneño Francisco de Paula González Vigil, texto que Hegan había obsequiado a Mora durante una visita a Londres ${ }^{49}$. En realidad, es difícil establecer cuán exacta es esta noticia autobiográfica, debido a que ser jansenista en España reflejaba, más que la pertenencia a una determinada corriente teológica, un conjunto de rasgos o prácticas religiosas características. Se podría entonces concluir que nuestro autor hacía referencia a un miembro de la Iglesia gaditana, próximo al catolicismo ilustrado. En todo caso, uno podría preguntarse también acerca de la identidad de este misterioso clérigo. Para algunos autores ${ }^{50}$, este jansenista enigmático debió ser don Cayetano María de Huarte ${ }^{51}$, literato y canónigo penitenciario de la catedral de Cádiz, quien realizó también labores de docencia en esa ciudad ${ }^{52}$. A pesar de que nos movemos en terrenos cercanos a la pura conjetura en cuanto a la significación de la expresión empleada por Mora en la carta a Hegan, Monguió no obstante no solo da por cierta esta influencia, sino que considera el supuesto ascendiente jansenizante en Mora como una

48 Carta de Mora a José Hegan, Londres, 22 de enero de 1855, reproducida por González 1961: 282-284. El pasaje relevante de la carta es el siguiente: «Mucho he agradecido el regalo que usted se ha dignado hacerme de la obra del doctor Vigil. Había oído celebrarla, y primaba mucho mi curiosidad, porque su asunto ha sido objeto de mis estudios, habiendo sido educado por un santo clérigo jansenista».

49 Quizá la obra en cuestión sea uno de los volúmenes de la Defensa de la autoridad de los gobiernos contra las pretensiones de la curia romana (seis volúmenes, 1848-1849).

50 Leopoldo Augusto Cueto, en su obra Poetas líricos del siglo XVIII, afirma que «Fue Huarte maestro de nuestro difunto amigo, el insigne académico don José Joaquín de Mora, el cual recordaba con especial complacencia algunas poesías de aquel ilustrado sacerdote» (1869: clxx). Monguió realiza una interpretación literal de esta afirmación (1967: 60), considerando que el sacerdote fue efectivamente profesor de nuestro autor. No obstante, si se tiene en cuenta el contexto, se podría entender esta alusión simplemente como un reconocimiento de que Mora consideró a su coterráneo como fuente de inspiración y modelo literario.

51 Huerta puede ser considerado como un católico ilustrado a pesar de que su formación intelectual inicial fue profundamente tradicionalista, haciendo un gran hincapié en la Teología Escolástica, y permaneciendo completamente al margen de las numerosas novedades culturales que el siglo XVIII depararía (Morgado García 1991: 14).

52 Huarte fue nombrado director del Colegio de Santa Cruz en Cádiz, cargo en el que permanecerá hasta 1788 (Morgado García 1991: 33). Este colegio estaba orientado sobre todo a la formación musical y en latín de los jóvenes que pertenecían al coro de la catedral gaditana. Es preciso señalar que en 1788 Mora contaba solamente cinco años de edad. Probablemente, el clérigo haya sido profesor posteriormente en otros centros educativos de esa ciudad, acerca de lo cual no tenemos mayor conocimiento. 
herramienta interpretativa para explicar ciertos aspectos de la biografía intelectual del escritor.

Supuesto que realmente esta influencia está presente en Mora, uno se podría preguntar en qué consistió. La mejor manera de responder a este interrogante, sobre todo cuando se trata de elucidar qué significado tuvo este término en España, es mediante la diferenciación entre jansenismo teológico y jansenismo histórico. El jansenismo teológico tiene sus inicios con las tesis propuestas por Cornelius Jansen en su Augustinus, publicado en 1640, dos años después de su muerte, mientras que el histórico es estipulativo; corresponde en cada caso a formas de religiosidad definidas como jansenistas por una determinada comunidad ${ }^{53}$. En el caso de la península ibérica esos rasgos eran la lucha teológica contra el molinismo, la aversión por la moral relajada o inspirada solamente por el temor de las penas del infierno, el catolicismo ilustrado antes mencionado, el regalismo y la lucha contra los jesuitas, a los que se reprochaba su probabilis$\mathrm{mo}^{54}$. Sin duda, el pretendido maestro de Mora, Cayetano de Huerta, en dos de sus Sátiras ${ }^{55}$, manifestará varios rasgos jansenizantes. Lo cierto es que se puede apreciar también en la biografía de nuestro autor algunas características antes mencionadas como un marcado antijesuitismo o su rechazo a formas de religiosidad populares, que quizá adquirió durante su primer periodo de formación.

Sobre su formación en el prestigioso Colegio de San Miguel de Granada, solo se sabe que realizó de manera sobresaliente la carrera de leyes. Como sucede a menudo, ya desde su primer recorrido intelectual el escritor descolló sobre el resto de sus condiscípulos por su «comprensión fácil y la aplicación suma» ${ }^{56}$. Es en esta época que la Universidad de Granada se convirtió en una de las principales cunas del pensamiento ilustrado en España y centro literario de gran irradiación en toda la península ibérica. Además de Mora, pertenecieron a esa generación ilustre de andaluces, Domingo Ruiz de la Vega; Francisco Javier de Burgos, el abate José Sicilia, Narciso Heredia (conde de Ofalia), y otros que Ferrer del Río consideraba «de no tan elevada suficiencia» (Ferrer del Río 1864). Posteriormente, a

53 Sobre esta distinción, ver Ceyssens: Le jansénisme. Considérations historiques préliminaires à sa notion, Nuove Ricerche storiche sul giansenismo, Roma, 1954, citado por Morgado García 1991: 106.

54 Appolis, E., Les jansenistes espagnols, Burdeos, 1966, pp. 9-39, citado por Morgado García 1991: 106.

55 "Sátira tercera: contra los errores en las morales y devociones falsas y supersticiosas», en Morgado García 1991: 219-229. "Sátira cuarta: a la obra del exjesuita Bonola», Liga de la teología moderna con la filosofía (¿1795?) (ibíd.: 233-237).

56 Ferrer del Río 1864. 
partir de $1800^{57}$, a Mora le tocará desempeñarse como regente de la cátedra de Lógica en esa casa de estudios ${ }^{58}$.

Una singular anécdota mencionada por Tomás Rodríguez Rubí durante una junta extraordinaria de la Real Academia Española celebrada en 1862 para honrar la memoria del escritor gaditano Francisco Martínez de la Rosa ${ }^{59}$, quien fuera director de esa institución, nos proporciona valiosa información acerca del curso de lógica que impartió Mora en ese centro universitario. Dentro de ese relato, se menciona que el rector de la Universidad y Colegio de San Miguel de Granada, Antonio Prieto Moreno, teniendo conocimiento de la gran capacidad intelectual del entonces adolescente Martínez de la Rosa le condujo, recomendó y puso bajo la hábil dirección del que se desempeñaba como catedrático de Lógica en el Colegio de San Miguel, don José Joaquín de Mora, en $1800^{60}$. Al año siguiente, llenó de asombro «á cuantos le vieron defender á la tierna edad de catorce aún no completos, unas conclusiones de lógica en latín, á cuya lengua tradujo correcta y elegantemente á Condillac, y cuyo tema creo que fue el de methodus analytica aptissima est ad veritates inquirendas» ${ }^{61}$. El texto que empleaba Mora para dar este curso era la célebre obra Lógica o los primeros desarrollos del arte de pensar, de Étienne Bonnot de Condillac, quizá en el original en francés ${ }^{62}$ o en la versión castellana del traductor ilustrado Bernardo María de Calzada, publicada en Madrid el año de $1784^{63}$.

57 Algunas fuentes señalan que Mora enseñaba en ese colegio cuando tenía apenas 17 años, lo que daría la fecha de 1800 (Discurso de Rodríguez Rubí: 9). Amunátegui, en su obra antes mencionada, dice, interpretando quizá un pasaje de las Memorias de Alcalá Galiano $(\mathrm{l}, 5)$, que el escritor gaditano comenzó a enseñar a partir de 1806 (1888: 16). Si tenemos en cuenta la exactitud de la información proporcionada por Rodríguez Rubí, que probablemente la obtuvo directamente de Martínez de la Rosa, se debería entonces privilegiar la fecha que él brinda frente a la de Amunátegui. El propio Martínez de la Rosa impartirá el curso de Filosofía Moral en esa casa de estudios en 1808, a la edad de 21 años.

58 Las principales biografías que hemos consultado solo señalan de la actividad académica de Mora en la Universidad de Granada que fue profesor de Lógica. Algunos autores incluso intercambiarán lógica por filosofía (Ferrer del Río, noticia necrológica), lo cual es bastante comprensible debido a la interrelación que existía en la época entre ambas materias.

59 Rodríguez Rubí 1862. El literato granadino fue presidente de la Real Academia de la Lengua durante más de veinte años (1839-1862), así como de otras instituciones académicas como el Ateneo de Madrid.

60 Rodríguez Rubí 1862: 9.

61 lbíd. La traducción al castellano de la oración en latín es: «el método analítico es el más apto para la búsqueda de la verdad». La conclusión, a la que se hace mención aquí, era un aserto o proposición que se defendía en las antiguas escuelas universitarias. La entrada correspondiente en el Diccionario de la lengua española.

62 Condillac 1798. Se puede especular que Mora empleaba únicamente para su exposición la Lógica o los primeros desarrollos del arte de pensar de Condillac, y no recurría a otros tratados de esta disciplina que se disponían en esta época. En escritos posteriores, él hará referencia ocasional de esta obra. Así, él muestra algún grado de conocimiento de esta obra en escritos posteriores.

63 Probablemente Mora haya utilizado esta translación, o con mucho menos certeza la curiosa obrilla de don Valentín de Foronda (1752-1822), Lógica de Condillac, puesta en diálogo y adicionada con un pequeño tratado sobre toda clase de argumentos y de sofismas (1794). 
Al parecer, las conclusiones que defendió Martínez de la Rosa correspondían a la primera parte del capítulo II de la Lógica ${ }^{64}$, «El análisis es el único método para adquirir conocimientos», donde el ilustrado francés afirma que la descomposición y recomposición del pensamiento y de las cosas sensibles para formar ideas exactas y distintas es el único procedimiento que nos proporciona verdaderos conocimientos, pues solamente este orden metodológico puede darles toda la claridad y toda la precisión de que ellas [las ideas] son susceptibles ${ }^{65}$.

La anécdota mencionada es reveladora en varios puntos. A diferencia de lo que sucedía en otros centros educativos de la época, la forma de enseñanza adoptada por Mora estaba exenta de las prácticas escolásticas, que, a decir de su contemporáneo, Blanco White, «se mantenían aún en la mayoría de las universidades» ${ }^{66}$. El libro de texto usual para el estudio de la filosofía en las universidades andaluzas era los Elementa Philosophiae, de un monje italiano llamado Lorenzo Altieri ${ }^{67}$. El propio Mora, años después, en un artículo suyo en la Crónica Política y Literaria de Buenos Aires, hará referencia a esta necesidad de recurrir a la dialéctica escolástica para comprobar los conocimientos en esta materia: «...hay universidades y colegios en que no se concede el título de buen lógico a quien no posee la llave de aquel profundo arcano: Barbara, Celarent, Darii, Ferio, Baralipton, Celantes, Dabitis, Fapesmo, Frisesomarum ${ }^{68}$.

Además, la referida anécdota describe bastante bien la manera en que se impartía el curso de Filosofía en el ámbito hispanoamericano en aquel entonces. Las ramas del saber enseñadas en las universidades españolas eran: 1) Filosofía, que incluía Lógica, Física y Metafísica; 2) Teología; 3) Derecho Romano; 4) Derecho Canónico; 5) Medicina ${ }^{69}$. La edad habitual de matricularse era entre los 14 y 15 años. Ningún estudiante podía pasar a ninguna de las facultades superiores si no había asistido dos años, como mínimo, a las escuelas de Filosofía. El primero de estos dos años estaba dedicado a la Lógica, curso que enseñaba Mora en la Universidad de Granada; el segundo, a los elementos de filosofía natural y a las nociones básicas de geometría necesarias para comprender las leyes generales del

64 Capítulo III de esta obra, «El análisis hace al alma justa [en sus percepciones]».

65 Condillac 1798: 26-27.

66 Según aparece en su Educación en España (1831). Las otras informaciones acerca de la situación de la instrucción en la península ibérica, que mencionamos a continuación, la hemos extraído de este escrito (Blanco White 2003: 276).

67 Fray Lorenzo Altieri, Elementa Philosophiae, Venecia, 1776, dos volúmenes, mencionado por Blanco White, ibíd.

68 Número 14, fecha 15 de abril de 1827.

69 Blanco White 2003: 275. La información que mencionamos aquí procede básicamente de este autor. 
movimiento y algunos teoremas de mecánica. Al final de estos dos años tenía lugar el examen para el grado de bachiller en artes. La prueba consistía en preguntas, hechas por los profesores, sobre las materias mencionadas anteriormente. Estos exámenes generalmente eran públicos y se realizaban en presencia del director del centro o rector.

A esto se añade la descripción bastante elocuente que proporciona Ferrer del Río de cómo ejerció él su tarea de profesor en aquella época: «No limitaba al desempeño de la cátedra sus afanes: hombre de iniciativa, y naturalmente colocado por su privilegiado entendimiento y su instrucción ya muy notable a la cabeza de la juventud ilustrada, sin tregua luchaba contra el atraso intelectual y las rancias preocupaciones, y del extranjero hacía traer obras, que por entonces no tenían expedito curso» (op. cit.). Si es del todo cierta la semblanza que hace Ferrer del Río sobre el magisterio de Mora en la Universidad de Granada, se puede apreciar en germen las constantes que caracterizan el recorrido intelectual del sabio gaditano: lucha contra todo lo que podría representar un atraso al progreso ilustrado, en especial contra el escolasticismo expresado aquí por la expresión rancias preocupaciones, un afán constante por conocer y dar a conocer los últimos adelantos en materia de filosofía y ciencia, que en cuanto al curso que impartió allí se expresaba en la adopción de la Lógica, de Condillac, a contracorriente de lo que sucedía en otros establecimientos superiores; en suma, la firme creencia en que los progresos en la educación representaba un avance moral para una nación.

Además de impartir esta materia, con alguna probabilidad Mora enseñó también el curso de Derecho sobre la base del Tratado de legislación civil y penal de Jeremy Bentham, pues según el testimonio del propio filósofo inglés ${ }^{70}$ :

En diferentes partes de España, se leyeron (puede imaginarse en secreto) ciclos de conferencias, de las cuales estas obras formaban los libros de texto: conferencias, sin otra motivación que las hacen tan naturales al patriotismo y la filantropía, pero tan sospechas y temibles a la legitimidad y el orden social. Una de estas conferencias tuvo por lector a un abogado, se trataba de Mora antes mencionado... ${ }^{71}$.

70 The Works of Jeremy Bentham, VIII [Edimburgo, 1843], p. 466.

71 «In different parts of Spain, were read, (it may be imagined with what secrecy,) courses of lectures, of which those works formed the text-books: lectures, upon those gratuitous terms which, to patriotism and philanthropy, are so natural, to legitimacy and social order, so suspected and formidable. One of these lectures had a Lawyer for its reader; it was that Mora above-mentioned...». Bentham y Bowring 1843: 466. 
Algunos años después, en 1820, tradujo del inglés: Los consejos que dirigió á las cortes y al pueblo español, de este mismo autor ${ }^{72}$, con el que mantuvo también un importante intercambio epistolar. Al igual que Bacon en el campo de la ciencia, Bentham en la concepción del ilustrado de Cádiz sentó las bases del derecho y la política en «la grande escuela de la observación, en el libro augusto de la naturaleza» ${ }^{73}$. No solo en la península ibérica el utilitarismo ejerció una profunda influencia. En América española encontramos importantes benthamianos como Santander, Miranda, Rivadavia, José María Luis Mora o el propio Simón Bolívar. Sin duda, Mora, en tanto traductor y difusor de Bentham, pudo capitalizar para sí parte del prestigio que gozaba el utilitarista inglés.

\section{La invasión napoleónica a España o los beneficios de la guerra}

La actividad académica que desempeñaba Mora en la Universidad de Granada fue interrumpida bruscamente por la invasión napoleónica a España en 1808. Siguiendo el general impulso patriótico, el escritor participará en diversas campañas contra el ocupante. El hispanista francés Camille Pitollet proporciona algunas luces sobre este agitado periodo de la vida de Mora. El escritor gaditano se uniformó y armó a sus expensas, y se enroló como simple soldado hasta alcanzar el título de alférez de caballería o lugarteniente de los dragones de Pavía ${ }^{74}$. Posteriormente, al vencer las tropas de Horace Sébastiani al Ejército de la Mancha comandado por José Urbina, Conde de Cartoajal, en Ciudad Real, el 27 de marzo de 1809, lo que quedaba de las fuerzas de este último, entre las que se encontraba el propio Mora, fueron asediadas por el general francés. Es en esas circunstancias que Mora es tomado prisionero y posteriormente conducido al depósito de prisioneros que existía en Autun, ciudad situada

\footnotetext{
72 Bentham 1820.

73 Crónica Política y Literaria de Buenos Aires, número 81, fecha 20 de agosto de 1827. Se trata de un artículo que el ilustrado gaditano consagró al rioplatense Florencio Varela con ocasión de un discurso pronunciado por este para agradecer el otorgamiento del grado de doctor. «En lugar de un escolástico embayetado, dice Mora, lleno de doctrinas que es incapaz de entender, porque no conoce el pueblo a que debieron aplicarse, erizado de textos del Digesto y del Código... [Varela] busca las fuentes del derecho... en la grande escuela de la observación, en el libro augusto de la naturaleza, en los trabajos de los Filanjieris, de los Beccarias y de los Bentham» (ibíd.).

74 Pitollet 1909: 54. Mellado (1848: 281), por su parte, brinda una novelada descripción del desprendimiento de Mora durante las circunstancias difíciles que vivió su patria, al punto de llegar a afirmar que él rechazó recibir grado alguno «a pesar del influjo de su familia y de las instancias de sus jefes», lo cual es poco probable si tenemos en cuenta las actas del matrimonio realizado en Francia, que describen al joven pretendiente con el grado militar antes mencionado. Ver Pitollet 1908: 252-261.
} 
en la Borgoña francesa ${ }^{75}$. Su confinación en suelo francés se prolongará hasta 1814.

El periodo pasado en cautiverio en Francia, acontecimiento aparentemente sin importancia en orden a una biografía intelectual del ilustre gaditano, en realidad tendrá un impacto significativo para la formación del novel escritor. Así, en la «Bibliografía moderna de España de 1824», publicada en la revista Ocios de Españoles Emigrados ${ }^{76}$, se puede leer que la «suerte que supo [Mora] convertir en su provecho, perfeccionándose en los conocimientos de las artes y ciencias», lo que da entender que el publicista realizó alguna clase de estudios durante el tiempo que permaneció en cautiverio. De forma aún más específica, el oponente de Mora en la polémica calderoniana, Böhl de Faber, señala que:

Su valor y una suerte infausta le arrebataron del patrio suelo, y por su desgracia vino a cursar las aulas francesas. Seducido por frases altisonantes, abandonó el paraíso de la imaginación por el desierto de la filosofía, é incomodado sin duda de la dicha que ha dejado atrás, trata de seducir a los inocentes con la manzana sobredorada de la llustración... ${ }^{77}$.

La caracterización que ofrece Böhl de Faber de este oscuro periodo de la vida de Mora, si no es en su mayor parte una pura ficción fraguada en el calor del debate, representa un gran interés, a pesar de la vaguedad de las expresiones empleadas por el romántico alemán. En esta descripción se da cuenta en primer lugar de que Mora realiza estudios formales en un centro de enseñanza de Francia, lo que mostraría además algún cambio en las condiciones de su cautiverio en ese país. Se puede deducir también, por las expresiones utilizadas por Böhl de Faber, que con ellos el escritor gaditano profundizó sus conocimientos en la filosofía de la llustración francesa o quizá más específicamente en la de los ideólogos ${ }^{78}$, en

75 Pitollet 1909: 54. Las circunstancias de la captura del escritor gaditano son oscuras. Igualmente, se desconoce dónde permaneció prisionero a partir de 1808. Según Pitollet, su traslado a Autun se produjo a partir de enero de 1814. No obstante, no se conoce cuándo fue exactamente capturado Mora. Pitollet, no obstante, no menciona en qué documento se basa él para afirmar que Mora se encontraba prisionero en Autun a partir de enero de 1814. Muy bien se podría especular que el escritor gaditano se encontraba allí unos meses antes.

76 Número 7 (octubre de 1824).

77 Citado por Pitollet (1909: 56). Ferrer del Río dice: «Por dicha el estudio tiene eficaz virtud para endulzar las situaciones más amargas, y Mora experimentolo de plano, dedicándose con más afán que nunca al cultivo de las bellas letras, su predilecta afición de siempre, aun cuando su anhelo de sabiduría le indujo hasta la vejez más adelantada a penetrar lo posible de todos los conocimientos humanos. Bien rico de ciencia tornó el año de 1814».

78 Como hemos visto anteriormente, Mora tenía conocimiento de pensadores ilustrados como Condillac durante el periodo que estuvo como profesor en Granada. Se podría especular entonces que los estudios filosóficos que realizó este escritor en Francia se orientaron a incorporar las corrientes de pensamiento de las que aún no tenía conocimiento, como podría ser la de los ideólogos franceses (Cabanis y Destutt de Tracy), a los que hará referencia 
desmedro de su temprano interés por la literatura. El retrato que realiza el emigrado alemán de esta tradición de pensamiento, además, no deja de ser singular por los adjetivos y frases que este autor emplea: desierto, altisonante, y su estudio es asimismo una desgracia para aquel que lo emprende.

Otro evento que marcará el derrotero intelectual de nuestro personaje fue su unión con Françoise Delauneux ${ }^{79}$. Esta ciudadana francesa lo secundará en las múltiples empresas que emprenderá nuestro autor en los dos continentes. En Londres con alguna probabilidad ayudó a su esposo en la elaboración de algunas de las numerosas obras editadas por Ackermann, y en Argentina y Chile la vemos dirigiendo instituciones educativas para mujeres, que se convertirán en la contraparte de los establecimientos para varones regentados por Mora. También se podría presumir su participación en las diversas traducciones al francés que realizó el gaditano a lo largo de su vida. Pitollet proporciona información bastante relevante sobre su enlace con esta francesa. Si el escritor gaditano, como lo señala el hispanista galo, se encontraba prisionero en Autun a partir de enero de 1814, es en ese mismo mes, más exactamente el día 19, que contrae matrimonio con Delauneux ${ }^{80}$. Esto hace que Pitollet se pregunte si Mora fue víctima del tradicional coup de foudre amoroso o más bien se trataría de un cálculo de razón ${ }^{81}$. En todo caso, ella sobrevivirá veinte tres años al deceso de Mora en 1864.

Debido a los más de tres años que permaneció en cautiverio, Mora no pudo participar directamente en uno de los acontecimientos políticos más importantes para la España del siglo XIX, la aprobación de la Constitución de $1812^{82}$. Esta carta magna representó el inicio de la historia

en diferentes publicaciones a partir de su regreso de Francia. En el periodo que él editará el periódico Crónica Científica y Literaria (1817-1820), se mencionará por ejemplo la siguiente letrilla (21-9-1819):

El Doctor de aulas añejas,

Cuyas góticas consejas

Le dieron loa y estima,

¿Qué dice si se le arrima,

El osado mozalbete

$Y$ en las cuestiones lo mete

De síntesis y análisis.

Aumentándole la crisis

Con Locke y Destutt Tracy?

Que no y que sí.

79 Llamada también Fanny, nombres que serán castellanizados muchas veces por Francisca. 80 Pitollet 1909: 55. Sobre las circunstancias particulares de este enlace, ver las actas de matrimonio publicadas en 1908 por el propio Pitollet (op. cit.).

81 Ibíd.

82 Esta carta magna se aprobó exactamente el 19 de marzo de 1812, día de San José. De allí el apelativo popular de la Constitución de 1812, conocida también como la Pepa. 
constitucional en España, además de sentar las bases formales del liberalismo español, que ejerció un profundo influjo por toda Europa y América hispana. Entre las características más notables de esta Constitución se encontraba el reconocimiento de la soberanía nacional, así como el principio de la división tripartita de poderes: el rey cogobernaba con sus ministros; el Poder Legislativo se delegaba principalmente a las Cortes, órgano de soberanía nacional, mientras que el aparato judicial dirimía los asuntos relativos a esta clase de conflictos ${ }^{83}$. Otro rasgo importante era su carácter representativo: los diputados eran elegidos por sufragio general, aunque en los hechos solo los varones adultos de una cierta clase social podían votar. A pesar de la novedad que representaba para el panorama político español, el texto presentaba graves defectos. El principal de ellos era la ausencia de una declaración de los derechos ciudadanos ${ }^{84}$, que se incluía en el proyecto inicial, pero que fue rechazada posteriormente ${ }^{85}$. A pesar de que Mora no siguió de cerca los avatares de la Carta Magna de 1812, él se inspiró de muchos pasajes de esta para redactar el proyecto de Constitución de 1828 en Chile. Aunque se ha discutido sobre el papel que tuvo Mora en la redacción de este documento constitucional de fuerte impronta liberal, lo cierto es que cuando se comparan ambos textos se puede encontrar más de una coincidencia. De esta forma, los artículos primero, décimo, y vigésimo segundo de la Constitución de Chile son casi copias conformes de los artículos segundo, cuarto, y tercero de la de $1812^{86}$. Los representantes del partido conservador de Chile, los Ilamados

83 Garriga y Lorente Sariñena, Cádiz, 1812: la Constitución jurisdiccional (2007), citado por Alonso 2012: 10.

84 Como lo señala Garriga y Lorente, la declaración de los derechos de los ciudadanos fue sustituida por un objetivo constitucional genérico «conservar y proteger por leyes sabias y justas la libertad civil, la propiedad y los demás derechos legítimos» para lograr «la felicidad de la Nación» y el «bienestar de los individuos», ibíd., citado por Alonso 2012: 10-11.

85 Esta Constitución tendrá un final aciago. En 1814, un grupo de diputados solicitó a Fernando VII, a través del ominoso «Manifiesto de los Persas», el retorno al antiguo régimen. Así, debido a enemigos que se encontraban al interior mismo del sistema constitucional, esta Carta Magna fue declarada nula el 4 de mayo del mismo año. La instauración del absolutismo fernandino provocó a su vez una fuerte persecución contra los principales gestores del movimiento liberal, persecución que se prolongó hasta 1820, año en el que, debido al levantamiento de Riego en Cabezas de San Juan, se restableció nuevamente esta Carta Magna. 86 El siguiente cuadro permite ver algunas de las coincidencias entre ambas cartas magnas:

\begin{tabular}{|l|l|}
\hline Constitución de 1812 & $\begin{array}{l}\text { Constitución de 1828 } \\
\text { (Mora) }\end{array}$ \\
\hline $\begin{array}{l}\text { Artículo 2. La Nación española es } \\
\text { libre e independiente, y no es ni } \\
\text { puede ser patrimonio de ninguna } \\
\text { familia, ni persona. }\end{array}$ & $\begin{array}{l}\text { Artículo 1. La Nación chilena [... ] } \\
\text { es libre e independiente de todo } \\
\text { poder extranjero. [...] No puede ser } \\
\text { el patrimonio de ninguna persona } \\
\text { ofamilia. }\end{array}$ \\
\hline
\end{tabular}

Fuentes: Luis Sánchez Agesta, Documentos constitucionales y textos políticos, Editora Nacional Cultura y Sociedad, Madrid, 1982, 220. Ossa Santa 2007: 124. 
pelucones, censuraron la Constitución de 1828, entre otras cosas porque el redactor principal de este texto suscribía una forma de liberalismo, que no correspondía a la realidad de aquel país. Además, consideraron contradictorios algunos puntos de la misma; por ejemplo, mientras el artículo tercero afirmaba que la religión del Estado era la católica romana, en otro se señalaba que ningún ciudadano podía ser «perseguido ni molestado por sus opiniones privadas» ${ }^{87}$.

\section{Periodista ilustrado durante el Trienio Liberal}

En 1814 volvió a su país, y establecido en Madrid intentó ejercer su profesión de abogado. La actividad intelectual que realizó el ilustrado en este periodo fue rica y variada. José Joaquín de Mora participó en la fundación del Ateneo Español en 1820, donde enseñó el curso de Derecho Natural $^{88}$. En los estatutos se mencionan los alcances que pretendía alcanzar esta institución: «Sin ilustración pública no hay verdadera libertad: de aquella dependen principalmente la consolidación y progresos del sistema constitucional y la fiel observancia de las nuevas instituciones. Penetrados de estas verdades, varios ciudadanos celosos del bien de su patria, apenas vieron felizmente restablecida la Constitución de la monarquía española, se propusieron formar una sociedad patriótica y literaria, con el fin de comunicarse mutuamente sus ideas, consagrarse al estudio de las ciencias exactas, morales y políticas, y contribuir, en cuanto estuviese a sus alcances, a propagar las luces entre sus conciudadanos» ${ }^{89}$. En 1821 , en esa institución, él pronunció el discurso de apertura, reproducido en diversas gacetas de la época, del curso de Derecho Natural, «Ciencia proscrita y abandonada durante tantos años» ${ }^{90}$.

Destaca también la intensa labor periodística que realiza en Madrid, la cual será una suerte de preámbulo de la que efectuará posteriormente en Londres y en distintas capitales americanas. Para entender la importancia

87 Ossa Santa 2007: 124.

88 Se trata del primer Ateneo, fundado en abril de 1820. Esta institución se constituyó como una sociedad patriótica y literaria, que defendía tanto la Constitución liberal como las artes y las ciencias. Gil Novales 1986: El Primer Ateneo: 1820-1823. Además del curso de Derecho Natural, se dictaba en esa institución el de Ideología (dentro de las Ciencias del Hombre), y otro, que tenía el sugerente título Verdadera Metafísica y Verdadera Filosofía, o Análisis Universal. La explicación que se proporcionaba en el Reglamento de esta institución acerca del curso era la siguiente: «Es la ciencia que resulta de todas las ciencias y de todas las artes que la sirven de base, y de las que también es reguladora» («Reglamento científico del Ateneo Español», 1820). El encargado del curso de Ideología era Antonio Fernández Vallejo. Esta institución desaparece en 1823, con la reinstauración del absolutismo fernandino. En 1835, surgirá de nuevo con el nombre de Ateneo Científico, Artístico y Literario de Madrid, empresa en la cual Mora también participó.

89 Estatutos 1820: 1, citado por Gil Novales 1986: 6.

90 El Censor, 5 de mayo de 1821, p. 267. 
que tiene la prensa para Mora, bastaría con analizar su visión acerca del medio que la hace posible: la imprenta. De acuerdo con nuestro personaje, la imprenta es para Mora el instrumento privilegiado de propagación de las luces, «arte maravilloso que atraviesa los intervalos de tiempo y de distancia, y distribuye igualmente a todos los hombres los conocimientos más diversos» ${ }^{91}$. La imprenta no era solamente el órgano de la opinión pública: ella la protege, la defiende, le suministra armas, y debe considerarse como la porción más preciosa de la herencia del género humano ${ }^{92}$. Cuando el pueblo no sabía más que lo que cada individuo podía aprender por sí solo; cuando había pocos libros y pocos hombres en estado de aprovechar de ellos, ni había opinión pública, ni aún siquiera público que mereciera este nombre, los tiranos y sus satélites estaban seguros ${ }^{93}$. Con la llegada de la prensa, se amplificaron aún más las características antes señaladas. La innovación que representaba la prensa para el panorama cultural y político de entonces, y su pertinencia en la implementación del proyecto ilustrado, no podían pasar desapercibidas para Mora. Antes de la aparición de las publicaciones periódicas los acontecimientos se percibían desde un punto de vista retrospectivo; al llegar la prensa, se pasó a contemplarlos desde el presente, a la manera en que un testigo percibe un hecho ${ }^{94}$. El escritor se convierte entonces en un testigo de lo que sucede en el presente; la significación misma de filósofo cambia y pasa a ser un espectador que construye sus principios sobre la base de innumerables observaciones individuales ${ }^{95}$. Mora, el periodista ciudadano, director de revistas y periódicos en Madrid, Londres y Santiago de Chile, encarnaba bastante bien este nuevo ideal del filósofo.

El 1 de abril de 1817 José Joaquín de Mora comenzó a publicar en la Imprenta de Repullés de Madrid un periódico con el nombre de Crónica Científica y Literaria, que, a decir de algunos de sus biógrafos, concitó el interés del público español y extranjero ${ }^{96}$. Esta gaceta salía dos veces a la semana (los martes y los viernes en 4 páginas), y tuvo un tiempo de vida relativamente prolongado, casi tres años (de abril de 1817 a marzo de

91 Crónica Política y Literaria de Buenos Aires, número 95, 6 de setiembre de 1827. Amunátegui llegó a decir que si Mora hubiese sido ateo, habría erigido un altar a la imprenta (12).

92 lbíd.

93 Ibíd.

94 Delon y otros 2001: 906.

95 Ibíd. El artículo correspondiente de Dumarsais en la Enciclopedia: «Le philosophe forme ses principes sur une infinité d'observations particulières» («El filósofo forma sus principios basándose en un infinidad de observaciones particulares)».

96 De acuerdo con Mellado (op. cit.), fue gracias a esta publicación que nuestro autor entró «en relaciones íntimas» con el célebre filósofo y jurisconsulto Jeremy Bentham, aunque otros intérpretes consideran que el lazo entre Mora y el pensador inglés se estableció mucho tiempo antes. 
1820), si la comparamos con otras publicaciones periódicas de la época. Sobre la presencia ilustrada en la Crónica, Francisco M. Tubino, en la Revista contemporánea, dijo: «Volteriana, por lo menos partidaria de Destutt-Tracy y de Condillac en filosofía, y con manifiestos resabios enciclopédicos.... ${ }^{97}$.

Según su prospecto, los redactores pretendían contribuir «á la ilustración científica y literaria, fuente de la verdadera cultura, y apoyo firme de la sana moral» ${ }^{98}$. Además de este propósito general, los autores del prospecto creían firmemente que la reparación de los daños causados por las guerras que habían desolado en ese entonces Europa, sobre todo durante la gran turbulencia producida por la campañas napoleónicas, pasaba necesariamente por acelerar «el estudio de cuantos descubrimientos se han hecho en Europa relativos á las artes industriales y productivas» ${ }^{99}$. Si para un lector contemporáneo podría parecer insensata esta equiparación entre conocimiento tecnocientífico y reparación o incluso erradicación de los daños ocasionados por las guerras, para un hijo de las luces como Mora era la falta de ilustración precisamente lo que producía los conflictos bélicos. ¿No era acaso la guerra el ejemplo más concluyente del declive moral de los pueblos? Así, el bienestar del pueblo es principalmente la desaparición de la guerra. Además, en una visión del Estado, que se configura como educador, que pretende sobre todo elevar el nivel cultural de la nación, ¿qué espacio queda para los conflictos y las hostilidades entre los pueblos?

Ciertamente, la Crónica constituía el principal vector de contenido científico en una España ensombrecida por el absolutismo fernandino. Como lo señala Asensio Manrique, con esta publicación Mora insertaba a esta nación dentro de la gran familia europea en la que prevalecían los principios del materialismo mecanicista como paradigma del progreso civilizador (2011: 112). No obstante, para hacer efectiva la implantación de ese ideal civilizatorio se debía antes analizar y asimilar los avances en ciencia y en tecnología que se estaban produciendo en aquel momento en la Europa de la Revolución industrial. Es en este contexto que se puede entender en parte la aversión casi visceral que sentía nuestro autor contra

9715 de enero de 1877. De esta publicación, el redactor de los Ocios tendrá también una opinión bastante favorable: «periódico muy acreditado en Europa, con el cual mantuvo el honor literario de España, mancillado en aquella época con la inmunda Atalaya de la Mancha» (Ocios 1814).

98 Prospecto de la Crónica, 1-3-1817. Elena Ausejo indica que la Crónica intentaba incorporar «la ciencia al patrimonio cultural de esta España casi desértica [en cuanto a sensibilidad científica] desde el punto de vista institucional». Elena Ausejo, «L'émergence de la science dans la fureur absolutiste: La Crónica Científica y Literaria (1817-1820)», en Sciences et Techniques en Perspective, ser. 2, vol. 4.2 (2000), p. 210, citado por Asensio Manrique 2011: 112.

99 Prospecto, ibíd. 
el escolasticismo, al que representará tantas veces como inútil y carente de todo contenido científico. A la inversa, Bacon, que él consideraba como el fundador de la ciencia moderna, despertaba toda su admiración ${ }^{100}$, a pesar de que en esa época ya se ponía en cuestión su importancia ${ }^{101}$. Así, en uno de sus artículos Mora afirmaba sobre el ilustre canciller de Inglaterra que «voces más elocuentes que la mía os han hablado del inmortal servicio que hizo á la ciencia, revelándole el instrumento poderoso con que debía elevarse á una región donde todavía no había penetrado» ${ }^{102}$.

A partir del número 309 (13 de marzo de 1820), esta publicación tomó el nombre de El Constitucional: o sea Crónica Científica, Literaria y Política. Con el cambio de título se producirá a su vez un cambio en cuanto al contenido: de un periódico de miscelánea literaria y divulgación científica pasará a ser uno con carácter abiertamente político ${ }^{103}$. Al realizar esta variación, además de ponerse en sintonía con los importantes cambios sociales que se estaban produciendo en la España de aquel entonces, presentía Mora que la modernidad científica a la que ellos aspiraban inicialmente no podía convivir con un régimen caracterizado por el despotismo y el fanatismo absolutista ${ }^{104}$. El redactor de los Ocios explica de este modo la razón de esta transformación de nombre y de orientación: «Restablecida

100 Expresar su admiración por Bacon, supuesto padre de la ciencia moderna, era casi un lugar común entre los ilustrados españoles. Jovellanos, en su Oración sobre el estudio de las ciencias naturales (1799), afirma: «Pero la gloria de abrir las puertas de la verdad de par en par estaba reservada al sublime genio de Bacon. Él fue quien con intrépida resolución y fuerte brazo quebrantó los que tantos esfuerzas y tantos siglos no pudieron descorrer, él quien aterró al monstruo de las categorías, y sustituyendo la inducción al silogismo, y el análisis a la síntesis, allanó el camino de la investigación de la verdad y franqueó las avenidas de la sabiduría; él fue quien primero enseñó a dudar, a examinar los hechos, y a inquirir en ellos mismos la razón de su existencia y sus fenómenos. Así ató el espíritu a la observación y la experiencia; así le forzó a estudiar sus resultados, y a seguir, comparar y reunir sus analogías; y así, llevándole siempre de los efectos a las causas, le hizo columbrar aquellas sabias admirables leyes que tan constantemente obedece el universo» (61). De igual forma, Feijoo, además de considerarlo «genio sublime» lo hará decir «que los químicos habían tomado a la verdad el rumbo que se debía seguir, conviene a saber, el de la experiencia». Teatro crítico, IV, VIII, 39, citado por Sarrailh 1979: 415. Esta opinión contrasta con la que se tiene de este pensador inglés en la actualidad. Así, en sus Estudios galileanos, Alexandre Koyré lo considerará más próximo a un primitivo que a Galileo o incluso a un escolástico: «Lo de "Bacon, iniciador de la ciencia moderna" es una broma, de mal gusto, que todavía repiten los manuales. En realidad, Bacon no comprendió nunca nada de la ciencia. Es crédulo y se halla totalmente desprovisto de espíritu crítico» (Koyré 1980 [2000]: 2, nro. 6).

101 Maistre, J. Examen de la philosophie de Bacon (1836, 1856), édit. Rodolphe de Maistre.

102 El Clamor Público, 5 de noviembre de 1851.

103 Esto a pesar de que la pretensión inicial de los editores, según lo manifiestan explícitamente en el prospecto del 1 de marzo de 1817, era que la Crónica estuviese «Exclusivamente consagrada á las ciencias y á la literatura».

104 Robert K. Merton mostró en diferentes trabajos el papel crítico del orden social democrático para el apoyo a la ciencia. En las modernas sociedades totalitarias, el antirracionalismo y la centralización del control institucional sirven para limitar los alcances de la actividad científica. De este modo, si bien la ciencia se puede desarrollar en diferentes estructuras sociales, es en democracia que el ethos de la ciencia moderna se integra en mayor medida. Véase La sociología de la ciencia: investigaciones teóricas y empíricas, 2 volúmenes. 
la Constitución Política en 1820, [Mora] manifestó de lleno sus ideas liberales en los dos periódicos que redactó, á saber, El Constitucional y la Minerva». Se encargaron de esta nueva versión, además de Mora, el liberal Agustín de Letamendi y don Manuel Eduardo de Gorostiza.

El acontecimiento que produjo este cambió de título en el periódico de Mora fue uno de los más dramáticos en términos de cambio social y político en Europa y en Hispanoamérica. El Trienio Liberal comienza el 1 de enero de 1820 con la proclamación de la Constitución de Cádiz en Las Cabezas de San Juan por el teniente coronel don Rafael del Riego. Inmediatamente, él procedió al restablecimiento de las autoridades constitucionales de la población. Pronto el grito de Cabezas se extendió también a otros lugares de España: La Coruña, Oviedo, Murcia, Zaragoza, Barcelona. El Conde de La Bisbal, encargado de reprimir la revuelta, prefirió proclamar la Constitución en Ocaña, lo que precipitó que Fernando VII prestase su juramento solemne ante las Cortes el 9 de julio, y se convirtiese así en el primer rey constitucional de ese país. El Trienio Liberal fue para algunos estudiosos un breve paréntesis en el que las fuerzas sociales se miden mutuamente, y hasta cierto punto admiten muy brevemente el juego de las contrarias ${ }^{105}$. El Trienio Liberal representó además una revolución en el ámbito intelectual, pues sirvió para completar la llustración, para igualarla aunque sea mediante la traducción de las obras más importantes con lo que había sido un cuarto de siglo antes la llustración ${ }^{106}$.

Un ejemplo de esto lo constituye el gran auge de la prensa periódica y de las traducciones que se produjo entonces en España. Hasta ese momento solo se traducían y publicaban los libros que se presentaban un carácter estrictamente científico, pero de esta tendencia estaban excluidas las obras que pertenecían a las ciencias humanas, las de carácter político, lo mismo las que contenían especulaciones filosóficas o teológicas. Todo esto va a cambiar radicalmente con el Trienio Liberal. Ahora se podía traducir y escribir prácticamente todo sin que por eso se cayese en la ilegalidad ${ }^{107}$. Adam Smith, Bentham, Destutt de Tracy, los grandes autores de la llustración francesa, penetran en España como lo hacen por otros países de Europa y América. El mismo Mora traducirá al célebre Barón de Holbach, representante de la Ilustración francesa más radical. La herencia ilustrada presente en este breve periodo constitucional se manifiesta también con una serie de medidas legislativas; quizá las más notorias son la supresión de los jesuitas en agosto de 1820, el utópico Reglamento

105 Gil Novales 1980: 66.

106 lbíd.

107 Gil Novales 1980: 72. 
general de instrucción pública de 1821, con el que se garantizaba al menos en teoría el acceso a la educación gratuita y universal, y el fomento y producción del comercio ${ }^{108}$. Después de cuatro gobiernos liberales, la gesta constitucional terminará con la invasión francesa en abril de 1823, el exilio de los principales liberales y el ahorcamiento de Riego, en noviembre de 1823.

Buena parte de la importancia que tendrá la Crónica para la historiografía posterior se debe a la polémica calderoniana, disputa literaria que desde 1817 Mora y su colega Antonio Alcalá Galiano sostuvieron con el emigrado alemán Juan Nicolás Böhl de Faber ${ }^{109}$. Por entonces uno de los fundadores del romanticismo germánico, August Wilhelm von Schlegel, ensalzaba las obras de Calderón de la Barca y de otros autores del Siglo de Oro ${ }^{110}$. Böhl de Faber, un culto comerciante asentado en Cádiz, donde había desposado a Frasquita Larrea, católica ferviente y lectora apasionada de los clásicos españoles y los románticos alemanes, sostuvo las mismas convicciones literarias que su ilustre compatriota. La disputa se inicia con una carta que envió Böhl de Faber a los editores de la Crónica, en la que él presentaba su desacuerdo con el empleo de la palabra ilustración en el prospecto de esta gaceta, lo que dejaba abierta a un posible utilización de carácter político de este término: «Inútil es manifestar los efectos perniciosos de semejante ilustración: ¿á quién no ha desengañado la Revolución francesa, qué fuerza podrán hacerle palabras que las lleva el viento» ${ }^{111}$. Para subsanar esto, el estudioso alemán proponía que se tuviera en cuenta una ilustración nacional, por referirse particularmente al carácter e índole de una nación, siendo esta a su juicio la más importante de todas. Mora se presentó a defender opiniones contrarias a las de este matrimonio, asumiendo posiciones cercanas a la escuela clásica francesa, denostando a Calderón, «aunque no sin confesarle perfección» "122. Esta querella se convirtió rápidamente en una confrontación de ideales políticos: el liberalismo incipiente de Mora contra el conservadurismo reaccionario del alemán ${ }^{113}$. El propio Alcalá Galiano, al comentar el papel de la Crónica en

108 P. 16

109 Sobre la polémica calderoniana, ver en primer lugar el texto antes mencionado de Pitollet, La querelle caldéronienne de Johan Nikolas Bohl van Faber et José Joaquín de Mora reconstituée d'apres les documents originaux. París, 1909.

110 Producto de esta revalorización de los autores del barroco hispánico es su célebre Teatro español, conjunto de traducciones contenidas en dos volúmenes (1803-1809). Schlegel también traducirá al otro gran referente de los románticos, William Shakespeare.

111 El prospecto aparece el primero de marzo de 1817, y la carta de Böhl de Faber es publicada en esa misma gaceta el 8 de abril de ese mismo año.

112 Alcalá Galiano, Memorias, tomo I, cap. 27.

113 Alcalá Galiano confesará esto en sus Memorias: «Mezclose con ella un tanto de política» (ibíd.). A esto se añade la defensa cerrada, monolítica, que hacían estos esposos al régimen absolutista: «Böhl y su señora eran acérrimos parciales de la monarquía al uso antiguo» (ibíd.). 
sus Memorias, señala que era la inclinación política, más que la científica y literaria declaradas en el título, la que absorbía casi por entero el interés de esta publicación ${ }^{114}$. Como lo señala Asensio Manrique, la ideología reaccionaria y espiritualista de Böhl de Faber no podía admitir el proyecto funcionalista de la Crónica, que se sustentaba en el nuevo paradigma mecanicista de la ciencia y de la técnica ${ }^{115}$. Incluso en este episodio de la vida de Mora se puede contemplar que su adhesión a los ideales ilustrados, como lo hace notar su oponente a lo largo del intercambio polémico, tenía incluso mayor relevancia que su afiliación, más bien circunstancial, al neoclasicismo:

Trabada esta contienda, me arrojé yo [Alcalá Galiano] a ella, más por celo de la fe del clasicismo profesada entonces por mí en su pureza, que por otras razones. Escribí algún artículo en la Crónica; respondiéronme desde Cádiz: volví a escribir, y me volvieron a responder... Ya más ardiente la disputa, entró por parte de nuestros contrarios el acusarnos de jansenismo y de amor a las reformas, cargos infundados si era como consecuencia de lo que en el litigio literario pendiente habíamos dicho, aunque en lo tocante a mi persona sobrado de fundamento ${ }^{116}$.

La acusación que realiza Böhl de Faber contra Mora y Alcalá Galiano es de interés notorio. En vez de acusarlos simplemente de ser defensores del rígido formalismo del neoclasicismo francés, va más allá de la crítica estética y les atribuye dos rasgos propios de buena parte de los ilustrados españoles: jansenismo y espíritu de reforma. No sin razón, Alcalá Galiano considera que estas acusaciones son infundadas si se circunscriben únicamente a la polémica literaria, pero son totalmente pertinentes en cuanto a sus convicciones filosóficas y políticas. Otro tanto se podría afirmar sin duda de José Joaquín de Mora.

A diferencia de la Crónica, el otro periódico que el ilustrado puso en circulación en aquel tiempo, la Minerva Española, tuvo desde sus inicios un matiz claramente político. En el prospecto publicado el 1 de abril de $1820^{117}$, el editor manifestaba el carácter constitucionalista y liberal, que

114 Asensio Manrique 2011: 113.

115 Asensio Manrique 2011: 112. Sobre la prensa durante el breve lapso liberal, véase también Cremades 1984: 429-446. Los varios partidos políticos de la época estaban representados por sendas publicaciones. Como señalan algunos autores, El Constitucional representaba al bando de los Comuneros.

116 Alcalá Galiano 1886: 268. Los subrayados en negrita son nuestros.

117 Antes de comenzar a editar una publicación periódica, los encargados imprimían un prospecto, donde se mencionaba entre otras cosas la fecha de publicación, los editores y, sobre todo, los fines y la orientación que pretendían darle. En el caso del prospecto de la Minerva, que no presenta ni fecha ni pie de imprenta, se informaba la aparición de un periódico con ese nombre, a partir de primeros de mayo de 1820, publicado por el gaditano José Joaquín Mora. 
pretendía imprimir al nuevo periódico, bastante contrario al despotismo y al fanatismo absolutista. Esta publicación, al igual que su contraparte francesa de parecido nombre, estaba destinada según el prospecto «á sostener el espíritu público en el camino de las nuevas instituciones» (Prospecto 1820). Para realizar esto, los editores se propusieron discutir «los puntos más importantes de las doctrinas políticas que reclamen la preferencia en nuestras circunstancias peculiares» (ibíd). A pesar de las buenas intenciones que acompañaban la creación de esta publicación, el tiempo de circulación de la Minerva fue bastante reducido, de mayo a julio de 1820. Se editaron así cuatro cuadernos, que constituyeron un primer tomo de 484 páginas, estampados al igual que la Crónica en la imprenta madrileña de Repullés. En octubre del mismo año, los editores ponen en conocimiento del público la continuación de un segundo tomo del periódico, lo que nunca, hasta donde sabemos, tuvo lugar.

\section{Traduciendo a vista de un volcán: el Ensayo sobre las preo- cupaciones, de Holbach}

La otra cara de la herencia ilustrada estaba representada por el número importante de traducciones que se realizaban en aquel entonces en España, con las que se esperaba situar a esta nación dentro de esta gran corriente de pensamiento y difundir los últimos avances en literatura, filosofía y ciencia en un país sediento de información. Lejos de encontrar el radicalismo ideológico que podemos presentar en la llustración francesa, en la península ibérica este fenómeno fue relativamente moderado y se integró sin mayor problema dentro del mundo católico tradicionalista. Ni en las dos épocas constitucionales (1810-1814 y 1820-1823), vemos la efusión de pensadores materialistas, deístas o incluso ateos, que podemos encontrar en los salones parisinos. No deja de sorprender entonces que durante el Trienio Liberal se publicaron algunas obras del barón de Holbach, conocido pensador ateo y materialista. Más sorprendente aún fue el papel que tuvo Mora en la difusión del pensamiento de este miembro de la llustración radical.

En 1823, don José Joaquín de Mora vertió al castellano con correcciones y adiciones el Ensayo sobre las preocupaciones escrito en francés por el barón de Holbach ${ }^{118}$. El título original de la obra de Holbach era

118 Ensayo sobre las preocupaciones, escrito en francés por el Barón de Holbach, y traducido con correcciones y adiciones por ]osé Joaquín de Mora. Assiduitate quotidiana et consuetudine oculorum assuescunt animi, neque admirantur, neque requirunt rationes earum rerum quas vident. Cícero de Nat. Deor. Lib. 2, Madrid, la Librería Extranjera de F. Denné, hijo, 1823, pp. 312-314. Casi de esta misma época datan otras traducciones a los escritos de este autor. Así, Manuel Díaz Moreno tradujo La moral universal o los deberes del hombre fundados en su naturaleza, publicada en 1812, y que salió a la luz nuevamente en 1821 sin autorización por 
Ensayo sobre los prejuicios [Essai sur les préjugés] ${ }^{119}$. No obstante, la traducción de Mora no era del todo desacertada, pues en el francés de la época un préjugé era «en términos metafísicos, un juicio realizado sin examen suficiente, una preocupación de la mente, que se efectúa sea por error de nuestros sentidos, sea por la opinión que nosotros concebimos, sea mediante el ejemplo, sea por dejarnos llevar de aquellos que nosotros frecuentamos» ${ }^{120}$. La lucha contra los prejuicios es indisociable a la propia caracterización de llustración, que dimos al comienzo de nuestro trabajo. La noción misma de progreso carecería de contenido si la razón no se afirmase como un combate constante contra el error, la superstición y la asunción pasiva de los argumentos de autoridad. El resumen que ofrece Mora de esta obra casi al inicio de la misma nos permite completar en cierta forma su propia concepción de llustración. Todos los males del hombre proceden de la ignorancia, de los errores y de los prejuicios o preocupaciones. El remedio de estos males es la verdad, que solo se logra con el cultivo de la filosofía y el espíritu crítico. De allí se puede entender la utilidad que tiene la filosofía en la política y en la moral. Un punto aún más controversial de la propuesta de Holbach, sobre todo para en una España en que la Iglesia mantenía un peso considerable, era la crítica del influjo de las preocupaciones religiosas y políticas en las costumbres de los hombres. Esto conducía al último punto de la obra: sin instrucción no pueden ser felices ni virtuosos. La obra, tal como la resume el escritor gaditano, termina con el optimismo ilustrado característico: «la verdad, tarde o temprano, debe triunfar del error» ${ }^{121}$.

El espíritu de la obra de Holbach correspondía a pesar de todo al ambiente de reforma que se vivía en España en aquel entonces. Mora, en la «Advertencia del traductor», muestra claramente esto:

Tendría ideas muy equivocadas acerca del estado presente de la sociedad el que opinase que la publicación de esta obrita del barón de Holbach es inútil en el día por hallarse destruidas o considerablemente debilitadas las preocupaciones que en ella se combaten. Ellas habrán quizá perdido en extensión, mas no en vigor ni en intensidad; y si se compara lo que dice el autor sobre las preocupaciones sacerdotales,

el mismo editor de la traducción de los Ensayos, el francés Felipe Denné, hijo. Esto muestra la existencia de un interés por el pensamiento de este autor durante el Trienio Liberal.

119 Holbach, P. H. D. (1793). Essai sur les préjugés ou de l'influence de l'opinion sur les moeurs et sur le bonheur des hommes (vol. 1).

120 «Préjugé, en termes de métaphysique, c'est un jugement porté sans un examen suffisant, une préoccupation d'esprit qui se fait ou par erreur de nos sens, ou par l'opinion que nous concevons, ou par l'exemple ou la persécution de ceux que nous fréquentons». Dictionnaire de Trévoux de 1771, citado por Delon 1995: 143. La traducción y el subrayado en negrita son nuestros.

121 Sumario de la obra 9. 
monárquicas y aristocráticas a lo que todos los días estamos viendo, se vendrá en conocimiento de la necesidad en que nos hallamos de hostilizar a tan poderosos enemigos ${ }^{122}$.

Para el literato español, el texto de Holbach constituía entonces una especie de antídoto para combatir los argumentos basados únicamente en la autoridad eclesiástica y política, sin que se realice un examen para analizar cuán valederas son estas asunciones. Más sorprendente aún es el llamamiento de Mora para combatir con la fuerza de la verdad y de la razón «tan poderosos enemigos». Al igual que el más radical de los ilustrados, el escritor gaditano considera como adversarios todos aquellos que teniendo poder utilizan este para impedir que el hombre adquiera autonomía, sean estos miembros de la Iglesia, de la monarquía o de la aristocracia. En esta perspectiva, él señala en esta misma «Advertencia» que «Cuanto más se debilite la fuerza de las preocupaciones, menos resistencia opondrán los que de ellas sacan su bienestar; y mientras menor sea esta resistencia, más fácil será el triunfo de la verdad, y menos víctimas se sacrificarán para asegurarlo» ${ }^{123}$. A pesar de esto, el traductor será consciente de la necesidad de adaptar la traducción. La España liberal de 1823 no era, a pesar de todo, la Francia revolucionaria de 1789. El barón de Holbach trabajaba a vista de un volcán, tiene a bien a señalar él. Su traductor en cambio ha presenciado la explosión, y trabaja a vista de los torrentes de lava que anuncian al mismo tiempo destrucción y fecundidad ${ }^{124}$.

122 Advertencia del traductor 5-7.

123 lbíd.

124 lbíd. Amunátegui dice que, a pesar de que don José Joaquín de Mora había prohijado el trabajo de un filósofo ateo y materialista, eso no fue impedimento para que vertiese al castellano tiempo después la obra Compendio de las vidas de los filósofos antiguos escrito por Fenelon, un obispo católico (1888, p. 29). Lo cierto es que el escritor gaditano, como lo señala él mismo en la Advertencia, realiza importantes modificaciones al escrito de Holbach, con lo que moderaba algunas opiniones del ilustrado francés. 


\section{REFERENCIAS BIBLIOGRÁFICAS}

\section{Diarios y periódicos}

La relación que sigue menciona solo los diarios y periódicos contemporáneos de don José Joaquín de Mora citados en el presente estudio y sus notas.

La América, Crónica Hispano-Americana. Madrid, 1857-1888.

The Atheneum. Londres, 1828-1921.

El Censor. Madrid, 1820-1822.

El Constitucional, o sea Crónica Científica, Literaria y Política. Madrid, 1820.

Correo Literario y Político de Londres. Londres, 1826.

Crónica Científica y Literaria. Madrid, 1817-1 820.

Crónica Política y Literaria de Buenos Aires. Buenos Aires, 1827.

El Clamor Público. Madrid, 1851.

El Mercurio Chileno. Santiago de Chile, 1828- 1829.

Mercurio Peruano. Lima, 1827-1834 y 1839.

Minerva Nacional. Madrid, 1820.

Museo Universal de Ciencias y Artes. Londres, 1824-1826.

Ocios de Españoles Emigrados. Londres, 1824-1 827.

Revista Científica y Literaria. Madrid, 1847.

Revista de España, de Indias y del Extranjero. Madrid, 1845-1866.

\section{Obras de don José Joaquín de Mora}

BARÓN DE HOLBACH [Paul Henri Thiry] (1823). Ensayo sobre las preocupaciones. Traducido con correcciones y adiciones por José Joaquín de Mora. Madrid: Librería Extranjera de F. Denné.

BENTHAM, Jeremy (1820). Consejos que dirige a las Cortes y al pueblo español.Traducción de José Joaquín de Mora. Madrid.

MORA, José Joaquín de (1842). Curso de Derecho Natural por don José Joaquín de Mora. Santiago de Chile: Imprenta Liberal.

(1849). Curso de Derechos del Liceo de Chile, por D. José Joaquín de Mora, Director de aquel Establecimiento. La Paz: Imprenta del Pueblo.

(1830). Curso de Derechos del Liceo de Chile, por don José Joaquín de Mora, director de aquel establecimiento. Santiago de Chile: Imprenta Republicana. 


\section{Referencias complementarias}

ALCALÁ GALIANO, Antonio (1845). Historia de la literatura española, francesa, inglesa e italiana en el siglo XVIII. Madrid: Imprenta de la Sociedad Literaria y Tipográfica.

cadas por su hijo.

(1886). Memorias de D. Antonio Alcalá Galiano publi-

AMUNÁTEGUI, Miguel Luis (1888). Don José Joaquín de Mora. Santiago de Chile: Imprenta Nacional.

APPOLIS, Émile (1966). Les jansénistes espagnols. Burdeos: Société Bordelaise de Diffusion de Travaux des Lettres et Sciences Humaines.

ASENSIO MANRIQUE, María (2011). «Mora en Londres: aportaciones al hispanoamericanismo». En Daniel Muñoz Sempere y Gregorio Alonso García (editores). Londres y el liberalismo hispánico. Madrid: Editorial Iberoamericana.

BENTHAM, Jeremy y BOWRING, John (1843). The Works of Jeremy Bentham. Edimburgo: William Tait.

BLANCO WHITE, José María (2003). Sobre educación. Madrid: Biblioteca Nueva.

BOBBIO, Norberto (2001). «Progrès scientifique et progrès moral». En Cités, nro. 3, pp. 119-136.

CANTERO GARCÍA, Víctor (2004). «Francisco Martínez de la Rosa y el romanticismo en el drama histórico: análisis, estudio y considera». Consultado el 21 de abril de 2012 de http://revistas.ucm.es/index.php/DICE/article/view/12911

CONDILLAC, Étienne Bonnot de (1798). Oeuvres de Condillac: La logique, ou les premiers développemens de l'art de penser. París: De l'Imprimerie de Ch. Houel.

(1784). La lógica, o los primeros elementos del arte de pensar. Madrid: Joaquín Ibarra Impresor de Cámara de S. M. y Ayuda de su Real Furriera.

CUETO, Leopoldo Augusto de (editor) (1871). Poetas líricos del siglo XVIII . Madrid: M. Rivadeneyra.

DELON, Michel (1995). «Réhabilitation des préjugés et crise des Lumières». En Revue Germanique Internationale, nro. 3, pp. 143-156.

DIDEROT, Denis (1976). CFuvres complètes. París: Hermann.

DUBNOV, Arie M. (2012). Isaiah Berlin: The Journey of a Jewish Liberal. Nueva York: Palgrave Macmillan. 
FIRODE, Alain (2001). Traité de dynamique de d'Alembert. París: Bellarmin/ Vrin.

FORONDA, Valentín de (1794). Lógica de Condillac, puesta en diálogo. Madrid: Imprenta de González.

FOUCAULT, Michel (1983). «How we behave». Consultado el 21 de abril de 2012 de http://www.vanityfair.com/culture/features/1983/11/sexualbehavior-198311

GAUCHET, Marcel (1985). Le désenchantement du monde: une histoire politique de la religion. París: Éditions Gallimard.

GIL NOVALES, Alberto (1980). El Trienio Liberal. Madrid: Siglo XXI Editores. GONZÁLEZ, Carlos (1961). Francisco de Paula González Vigil: el precursor, el justo, el maestro. Lima: Escuela de Artes Gráficas del Politécnico Nacional Superior José Pardo .

GONZÁLEZ ALONSO, Nuria (2012). «Rafael del Riego: un liberal asturiano que apoyó las Cortes de Cádiz y la Constitución de 1812». Consultado el 21 de abril de 2012 de http://www.academia.edu/3037121/La_implantacion_del_liberalismo_en_los_ayuntamientos_de_la_Asturias_urbana_ cambio_o_continuidad

HARE, Richard M. (1952). The language of Morals. Oxford: Clarendon Press.

HOLBACH, Paul Henri Dietrich von (1793). Essai sur les préjugés ou de l'influence de l'opinion sur les moeurs et sur le bonheur des hommes. París: Chez J. Desray.

JOVELLANOS, Gaspar Melchor de (1964). Obras selectas. Zaragoza: Editorial Ebro.

KANT, Immanuel (2003). El conflicto de las facultades, en tres partes. Madrid: Alianza Editorial.

(2004). «¿Qué es la ilustración?» y otros escritos de ética, política y filosofía de la historia. Madrid: Alianza Editorial.

KENTER, Lucas Petrus (1972). M. Tullius Cicero, De legibus: A commentary on book I. Ámsterdam: Hakkert.

KNIGHT, Charles (1867). The English Cyclopaedia: Division. Londres: Bradbury, Evans.

KORSHIN, Paul J. (1973). «Ana-books and intellectual biography in the eighteenth century». En Harold E. Pagliaro (editor). Racism in the Eighteenth Century. Cleveland: Press of Case Western Reserve University.

KOYRÉ, Alexandre (2000). Estudios galileanos. México D. F.: Siglo XXI Editores. 
LESSING, Gotthold Ephraim (2008). La educación del género humano. Barcelona: Azul Editorial.

LLORENS, Vicente (1968). Liberales y románticos: una emigración española en Inglaterra, 1823-1834. Valencia: Editorial Castalia.

Alianza Editorial.

(1969). Literatura española del siglo XIX. Barcelona:

MAISTRE, Joseph Marie Compte de (1853). Examen de la philosophie de Bacon: où l'on traite différentes questions de philosophie rationelle: ouvrage posthume. París: Pélagaud.

MELAMED, Yitzhak y LIN, Martin (2013). «Principle of sufficient reason». Consultado el 21 de abril de 2013 de http://plato.stanford.edu/entries/ sufficient-reason

MELLADO, Francisco de Paula (1847). Diccionario universal de Historia y de Geografía. Madrid: Establecimiento Tipográfico de D. Francisco de Paula Mellado.

MERTON, Robert King (1977). La sociología de la ciencia. Madrid: Alianza Editorial.

MOLINA MARTÍNEZ, José Luis (1998). Anticlericalismo y literatura en el siglo $X I X$. Murcia: Editum Ediciones.

MONGUIÓ, Luis (1967). Don José Joaquín de Mora y el Perú del ochocientos. California: University of California Press.

MORGADO GARCÍA, Arturo (1991). Iglesia e llustración en el Cádiz del siglo XVIII: Cayetano Huarte (1741-1806). Cádiz: Universidad de Cádiz.

MUÑOZ SEMPERE, Daniel y GARCÍA, Gregorio Alonso (2011). Londres y el liberalismo hispánico. Madrid: Editorial Iberoamericana

NEMO, Philippe (1998). Histoire des idées politiques dans l'Antiquité et au Moyen Âge. París: Presses Universitaires de France.

NIETZSCHE, Friedrich Wilhelm (1996). Humano, demasiado humano. Un libro para espíritus libres (fragmentos póstumos). Madrid: Ediciones Akal.

OSSA SANTA CRUZ, Juan Luis (2007). «La actividad política de Francisco Antonio Pinto: 1823-1828. Notas para una revisión biográfica». En Historia, nro. 40, vol. 1, pp. 91-128.

PITOLLET, Camille (1909). La querelle caldéronienne de Johan Nikolas Böhl von Faber et José Joaquín de Mora. París: Félix Alcan.

(1908). «El casamiento de Don J. J. de Mora en Autun en 1814 según las actas originales». Revista de Archivos, Bibliotecas y Museos, nros. 9-10. 
RODRÍGUEZ RUBÍ, T. (1862). Discurso que en la junta pública extraordinaria celebrada por la Real Academia Española para honrar la memoria de su último director perpetuo, el excelentísimo Señor D. Francisco Martínez de la Rosa, leyó el Illmo. Sr. D. Tomás Rodríguez Rubí, académico de número, el día 28 de febrero de 1862. Madrid: Imprenta de Manuel Galiano.

ROMERA VALERO, Ángel (2010). «La trayectoria periodística de Félix Mejía durante el trienio liberal. Primera parte: de la colmena y la periódicomanía a el cetro constitucional (1820-1821)». Cuadernos de llustración y Romanticismo, nro. 16.

RUBIO CREMADES, Enrique (1984). «"La Periodicomanía” y la prensa madrileña en el Trienio Liberal». En Anales de literatura española, nro. 3, pp. 429-446.

RUIZ SALVADOR, Antonio (1971). El Ateneo científico, literario y artístico de Madrid (1835-1885). Londres: Tamesis Books.

SÁNCHEZ AGESTA, Luis (1982). Documentos constitucionales y textos políticos. Madrid: Editora Nacional, Cultura y Sociedad.

SARRAILH, Jean (1979). La España ilustrada de la segunda mitad del siglo XVIII. México D. F.: Fondo de Cultura Económica.

SCHAER, Roland (2007). Linvention des musées. París: Gallimard.

TREASE, Billy D. (1953). José Joaquín de Mora: A Spaniard Abroad. Disertación doctoral, Universidad de Michigan.

ZINNY, Antonio \& Funes, G. (1869). Efemeridografía argirometropolitana hasta la caída del gobierno de Rosas. Contiene el título, fecha de su aparición y cesación, formato, imprenta, número de que se compone cada colección, nombre de los redactores que se conocen, observaciones y noticias biográficas sobre cada uno de estos, y la biblioteca pública ó particular donde se encuentra el periódico. Buenos Aires: Imprenta del Plata. 